\title{
A Jump-Diffusion Approach to Modeling Credit Risk and Valuing Defaultable Securities
}

\author{
Chunsheng Zhou ${ }^{\dagger}$
}

March 1997

${ }^{\dagger}$ Federal Reserve Board, Mail Stop 91, Washington, DC 20551. Tel: (202) 452-3328, Fax: (202) 452-5296, E-mail: czhou@frb.gov. The author would like to thank John Campbell, Greg Duffee, Matt Pritsker, Krishna Ramaswamy, René Stulz, and seminar participants at the Federal Reserve Board and the NBER for helpful discussions and comments. The analysis and conclusions set forth in this paper are those of the author and do not indicate concurrence by other members of the research staffs, by the Board of Governors, or by the Federal Reserve Banks. 


\begin{abstract}
Since Black and Scholes (1973) and Merton (1974), structural models of credit risk have relied almost exclusively on diffusion processes to model the evolution of firm value. While a diffusion approach is convenient, in empirical application, it has produced very disappointing results. Jones, Mason, and Rosenfeld (1984) find that the credit spreads on corporate bonds are too high to be matched by the diffusion approach. Also, because the instantaneous default probability of a healthy firm is zero under a continuous process, the diffusion approach predicts that the term structure of credit spreads should always start at zero and slope upward for firms that are not currently in financial distress, but the empirical literature shows that the actual credit spread curves are sometimes flat or even downward-sloping.

If a diffusion approach cannot capture the basic features of credit risk, what approach can? This paper develops a new structural approach to valuing default-risky securities by modeling the evolution of firm value as a jump-diffusion process. Under a jump-diffusion process, a firm can default instantaneously because of a sudden drop in its value. With this characteristic, a jump-diffusion model can match the size of credit spreads on corporate bonds and can generate various shapes of yield spread curves and marginal default rate curves, including upward-sloping, downward-sloping, flat, and hump-shaped, even if the firm is currently in good financial standing. The model also links recovery rates to firm value at default in a natural way so that variation in recovery rates is endogenously generated in the model. The model is also consistent with many other stylized empirical facts in the credit-risk literature.
\end{abstract}


There are two basic approaches to modeling corporate default risks. One approach, pioneered by Black and Scholes (1973) and Merton (1974) and extended by Black and Cox (1976), Longstaff and Schwartz (1995), and others, explicitly models the evolution of firm value observable by investors. The firm defaults when its market value falls below certain exogenously given threshold level or the value of its debt. This approach for valuing risky debt is called a structural approach by Duffie and Singleton (1995) and has been applied in Geske (1977), Ingersoll (1977a, 1977b), Merton (1977), Smith and Warner (1979), Cooper and Mello (1991), Hull and White (1992), Abken (1993), and many other papers.

One critical common assumption of the Merton-Black-Cox-Longstaff-Schwartz approach is that the evolution of firm value follows a diffusion process. Under a diffusion process, because a sudden drop in firm value is impossible, firms never default unexpectedly (i.e., by surprise). ${ }^{1}$ The validity of this implication is questionable. If a firm cannot default unexpectedly and if it is not currently in financial distress, its probability of defaulting on very short-term debt is zero and therefore, its short-term debt should have zero credit spreads and its term structure of credit spreads should slope upward at the short end. This implication of the diffusion approach is strongly rejected. Credit spreads on typical short term bonds are much larger than zero. Moreover, Fons (1994) and Sarig and Warga (1989) even find that the yield spread curves of certain kind of bonds are flat or even downward sloping. The empirical application of a diffusion approach has yielded very disappointing results. Jones, Mason, and Rosenfeld (1984) find that the credit spreads on corporate bonds are generally too high to be matched by this approach.

The implication that a firm has a constant value upon default in the typical diffusion approach (e.g., Longstaff and Schwartz) is also problematic. ${ }^{2}$ On the one hand, this approach emphasizes the central role of firm value in the determination of default. On the other hand, the approach cannot allow the variation in the recovery rate of a risky bond to

\footnotetext{
${ }^{1}$ More precisely, the time of default is accessible under a diffusion process, meaning that there is an increasing sequence of stopping times that converges to the default time, and therefore 'foretells' the event of default.

${ }^{2}$ Merton's (1974) model is an exception. Under some very restrictive assumptions of his model, such that a firm has only one bond issue and does not default until the maturity of the bond, the remaining value of a firm upon default is stochastic.
} 
depend on the firm's remaining value at default.

Another alternative approach, adopted by Duffie and Singleton (1994), Jarrow, Lando, and Turnbull (1994), Jarrow and Turnbull (1995), Madan and Unal (1994), and others does not consider the relation between default and firm value in an explicit (or structural) way. This approach is called the reduced-form approach. In contrast to the Merton-Black-CoxLongstaff-Schwartz's structural approach, the reduced-form approach treats default as an unpredictable Poisson event involving a sudden loss in market value so default events can never be expected. ${ }^{3}$ For example, Duffie and Singleton (1994) assume that default occurs at a risk-neutral hazard rate $h_{t}$ at any time $t$, meaning roughly that the conditional riskneutral probability at time $t$ of default over a small time interval $\Delta t$, given no default before $t$ is $h_{t} \Delta t$.

The attractive property of the above reduced-form approach is its tractability. However, it is not clear from the approach what the link or mechanism is between firm value and corporate default. For example, since the hazard rate of default in the reduced-form approach is modeled as an exogenous process, nobody knows what determine the "mysterious" hazard rate from this approach. Also, the implication that firms can only default "by surprise" seems unrealistic.

In summary, a reduced-form approach is usually more flexible to fit the observed credit spreads, while a structural approach often generates more conceptual insights on default behavior. Neither a default approach nor a structural approach (based on a diffusion process) captures both expected and unexpected defaults. From a theoretical perspective, a structural approach based on a diffusion process completely rules out the use of a hazard default rate which is common in the reduced-form approaches, because any such hazard rate would be zero before default and infinity at default. ${ }^{4}$

Can we have a model which not only has the flexibility of the reduced-form approach to fit the data but also provides the theoretical insights on the economic mechanism behind default events of the traditional structural approach? Can we have a model which allows

\footnotetext{
${ }^{3}$ That is, the time of default is always an inaccessible stopping time.

${ }^{4}$ See Duffie and Singleton (1995) for a detailed discussion on this issue and the distinction between expected defaults and unexpected defaults.
} 
for both expected and unexpected defaults in a single framework? How can we reconcile the different implications of the traditional reduced-form and structural approaches?

To answer these questions, this paper develops a simple yet flexible structural approach to valuing risky debt by modeling the evolution of firm value as a jump-diffusion process. Under a jump-diffusion process, a default can happen expectedly because of slow but steady declines in firm value. A default can also occur unexpectedly because of a sudden drop in firm value. This flexibility has a number of interesting implications, including: 1) The term structure of credit spreads can be upward sloping, flat, hump-shaped, or downward sloping. Some of these shapes (flat and downward-sloping) are not possible in structural models based on diffusion processes unless a firm is in financial distress. 2) Default probabilities and credit spreads on very short-term bonds of good quality firms can be larger than zero. In particular, holding constant the total volatility of the dynamics of firm value, the existence of jump risks can substantially raise the credit spreads of bonds over a wide maturity range. 3) The remaining value of a firm at default is a random variable. Since what bondholders receive upon default are mainly determined by the remaining value of the firm, the randomness of firm value at default implies that a jump-diffusion model can generate variations in recovery rates endogenously. 4) The recovery rate of a defaulted bond is positively correlated with the credit quality of the bond before default. These implications are consistent with a number of stylized empirical regularities detailed in Fons (1994), Sarig and Warga (1989), Jones, Mason, and Rosenfeld (1984), Altman (1989), and many others.

The importance of jump processes in pricing risky bonds was also noticed by Mason and Bhattacharya (1981). In Mason and Bhattacharya's model, the evolution of firm value follows a pure jump process with jump amplitude following a binomial distribution. Our jump-diffusion model is more flexible and more general. It is also more realistic. In our model, the dynamics of firm value have two random components: a continuous diffusion component and a discontinuous jump component. The jump amplitude follows a log-normal distribution rather than a binomial distribution.

The remainder of this paper is structured as follows. Section 1 presents the basic economic framework. Section 2 provides closed-from solutions to simplified models in which a default can only occur at the maturity of the debt as in Merton (1974). Section 3 solves the 
general models in which a default may occur at any time. The implications of the model are are illustrated in Section 4. Section 5 gives a useful application of our general pricing methodology, i.e., pricing credit default swaps. Section 6 extends our economic framework to allowing for stochastic interest rates. Section 7 concludes.

\section{The Basic Model}

By extending Merton-Black-Cox-Longstaff-Schwartz approach and modeling the evolution of firm value as a jump-diffusion process, this section builds a continuous-time valuation framework for risky debt. The basic assumptions are listed and discussed below. Some of them parallel those of Merton (1974), Black and Cox (1976), and Longstaff and Schwartz (1995).

Assumption 1: Let $V$ denote the total market value of the assets of the firm. The dynamics of $V$ are given by the following jump-diffusion process

$$
d V / V=(\mu-\lambda \nu) d t+\sigma d Z_{1}+(\Pi-1) d Y
$$

where

$\mu, \nu, \lambda$, and $\sigma$ are positive constants;

$Z_{1}$ is a standard Brownian motion;

$d Y$ is a Poisson process with intensity parameter $\lambda$;

$\Pi>0$ is the jump amplitude with expected value equal to $\nu+1$, and

$d Z_{1}, d Y$, and $\Pi$ are mutually independent.

Because $\nu$ equals the expected value of jump component $(\Pi-1), \mu$ in the above equation represents the expected instantaneous rate of change of firm value.

We assume that $\Pi$ is an i.i.d. log-normal random variable, such that

$$
\ln (\Pi) \sim N\left(\mu_{\pi}, \sigma_{\pi}^{2}\right)
$$

This assumption implies that

$$
\nu:=E[\Pi-1]=\exp \left(\mu_{\pi}+\sigma_{\pi}^{2} / 2\right)-1
$$


The diffusion process in equation (1) characterizes the "normal" fluctuation in firm value, due to gradual changes in economic conditions or the arrival of new information which causes marginal changes in the firm's value. The jump component describes the sudden changes in firm value due to the arrival of important new information which has a large effect on firm's market value. Given the fact that a firm's value moves almost continuously most of the time and that the market value of a firm may drop dramatically in the event of default, a jump-diffusion process for firm value seems appropriate for modeling a firm's default risk. For a detailed discussion of jump-diffusion processes, see, for example, Kushner (1967) and Merton (1974).

Assumption 2: The capital asset pricing model (CAPM) holds for equilibrium security returns and the jump component of firm's value equation (1) is purely firm-specific and is uncorrelated with the market.

The jump-diffusion process was introduced into the derivative pricing literature by Merton (1976). According to Merton, there generally does not exist a set of portfolio weights that will eliminate the "jump" risk. A Black-Scholes hedge will not be riskless even in a continuous-time setup. To validate the Black-Scholes "risk-neutral" argument, some extra restrictions on the economy and the jump process must be imposed. If the jump component represents nonsystematic risk, a portfolio which removes the risk of diffusion component (i.e., $d Z_{1}$ does not appear in the return process of the portfolio) will have a zero "beta." By the CAPM, the expected return on that portfolio must equal the riskless rate. The jump risk will therefore not receive a risk premium.

Assumption 3: The Modigliani-Miller theorem that the value of the firm is invariant to its capital structure obtains.

This is a standard assumption in the literature ${ }^{5}$, which requires that changes in capital structure, such as debt/equity ratio and payments of coupons and principle, do not affect the firm's value $V$.

Assumption 4: We assume perfect, frictionless markets in which securities trade in continuous time. Arbitrage opportunities do not exist.

According to Harrison and Pliska (1981), the nonexistence of arbitrage opportunities is

\footnotetext{
${ }^{5}$ See Merton (1974) and Longstaff and Schwartz (1995).
} 
equivalent to the existence of equivalent martingale measures. Most standard approaches in the derivative pricing literature can then be used in valuing default-risky debt.

Assumption 5: There exists a positive threshold value $K$ for the firm at which financial distress occurs. The firm continuous to operate and to be able to meet its contractual obligations as long as $V>K$. However, if its value $V$ falls to or below the threshold level $K$, it defaults on all of its obligations immediately and some form of corporate restructuring takes place.

This assumption follows Black and Cox $(1976)^{6}$ and Longstaff and Schwartz (1995). However, in the Black-Cox-Longstaff-Schwartz framework, because the firm's value $V$ has a continuous time path, $V$ is always equal to $K$ in the event of default. In our model, because $V$ has a jump component, in the event of default, it can be a random number distributed in the whole interval of $(0, K]$. Because of this property, it is quite natural in our model to randomize the recovery rate of debt issues and to link this rate to firm's value if a default occurs.

An important implication of the assumption is that default occurs for all debt contracts simultaneously. Longstaff and Schwartz (1995) provide a detailed discussion of institutional arrangement and corporate restructuring in the default.

Assumption 6: The firm issues both equity and debt (bonds). If it defaults during the life of a bond, the bond holder receives $1-w\left(X_{s}\right)$ times the face value of the security at maturity $T .{ }^{7}$ Here $s=\min (\tau, T)$ with $\tau$ being the time of default and $X:=V / K$ is the ratio of firm's value $V$ to the threshold level $K$.

In practice, $w$ is usually a non-increasing function of $X$, that is the inequality $w^{\prime}(X) \leq 0$ holds. The factor $w$ represents the percentage writedown on a bond if there is a reorganization of the firm. When $w=0$, there is no writedown and bondholders are not affected by

\footnotetext{
${ }^{6}$ Black and Cox (1976) assume that $K$ is a deterministic function of time while we assume that $K$ is a constant here. Assuming that $K$ is a deterministic function of time does not affect the basic structure of our model.

${ }^{7}$ This assumption follows Longstaff-Schwartz (1995). The assumption that bondholders will be paid at the maturity time even though a default may have occurred before that time is made for expositional convenience. One can easily relax this assumption by assuming that bondholders get paid immediately at default time if a default occurs in the life of the bond without affecting the basic structure of the model.
} 
the firm's reorganization. When $w=1$, bondholders receive nothing in a reorganization.

In general, $w$ will differ across various bond issues in the firm's capital structure. For example, Altman and Bencivenga (1995) find that the average recovery rate $(1-w)$ for secured, senior, senior subordinated, cash-pay subordinated, and non-cash-pay subordinated debt for a sample of defaulted bond issues during the 1985 to 1994 period is $0.593,0.508$, 0.365, 0.306, and 0.187, respectively. Similar results are also found by Altman (1992), Betker (1992), and Franks and Torous (1994). It is important to note that even for the same class of bond issues, the writedown $w$ differs significantly across different time periods and different firms. Altman and Bencivenga (1995) reports, for example, the average recovery rate for the defaulted issues of secured debt is 0.827 in 1989 but is only 0.120 in 1987 . A number of factors may have contributed to this large disparity, but the firm's value in the event of default is certainly important. Most valuation models do not explain the variation in writedown ratios for the same kind of bonds. A primary advantage of our model is that is considers such variation in a natural way.

Note that even though we do not explicitly write $w$ as a function of the firm's capital structure and the class of the debt issue for notational simplicity, $w$ should be understood as bond specific. For example, a senior bond will have a different $w$ function from a junior bond.

Assumption 7: The short-term riskfree interest rate $r$ is constant over time.

This assumption is made for convenience only and will be relaxed in Section 6 .

Assumption 1 and the definition that $X=V / K$ yield immediately

$$
d X / X=(\mu-\lambda \nu) d t+\sigma d Z_{1}+(\Pi-1) d Y
$$

Let $H$ be the price of any derivative security with payoff at time $T$ contingent on the firm's $X$. Using Merton's (1976) result, we know that under the assumption that the jump risk is not systematic and that arbitrage opportunities are excluded, the derivative price $H$ must satisfy the following partial differential equation (PDE):

$$
\frac{1}{2} \sigma^{2} X^{2} H_{X X}+(r-\lambda \nu) X H_{X}-r H+\lambda E_{t}[H(X \Pi, T)-H(X, T)]=H_{T} .
$$

The above equation depends on neither the risk-aversion coefficient nor the physical drift of the firm's $X$, as we expected from standard no-arbitrage approach for pricing derivative 
securities. Theoretically, the value of any derivative security can be obtained by solving equation (4) subject to appropriate boundary conditions. However, in practice, a closedform solution does not always exist, thus numerical approaches are sometimes necessary.

The above assumptions provide a general framework for valuing default-risky securities. Analytical solutions to security prices are not easily found in such a general framework. To make some technical preparation and to provide some intuition, we consider a simplified model with a closed-form solution before trying to solve the general valuation problem.

\section{A Closed-form Solution to a Simplified Model}

This section presents a valuation formula for default-risky discount bonds in a simplified framework with a different timing of default event. That is, Assumption 5 in the previous section is replaced by

Assumption 5': The firm has two classes of claims: (a) discount bonds with a single maturity $T$ and (b) the residual claim, equity. The firm promises to pay the face value of each bond ( $\$ 1$ ) at the maturity date $T$. If the firm's value at $T$ is not greater than $K$ (this means that the firm is not able to pay all of its debt), the firm defaults and the bondholders divide the firm to recover the value of their bondholdings.

This assumption simplifies the model because the possible default time is now given rather than a stochastic stopping time. This assumption is similar to the one made by Merton (1974).

Under Assumptions $5^{\prime}$, the price $B(X, T)$ of the bond with a promised final payment $\$ 1$ at time $\mathrm{T}$ is characterized by PDE (4) subject to the condition at $T=0$ that

$$
B(X, 0)=I_{X>1}+[1-w(X)] \cdot I_{X \leq 1}
$$

where $X:=V / K$ is defined as before and $I$ represents the indicator function, that is

$$
I_{s t h}= \begin{cases}1, & \text { if } \text { sth is true } \\ 0, & \text { otherwise }\end{cases}
$$

Lemma 1 Under Assumptions 1-4, 5', and 6-7, the bond price $B(X, T)$ is given by

$$
B=\exp (-r T) E^{Q}\left[I_{X_{T}>1}+\left(1-w\left(X_{T}\right)\right) I_{X_{T} \leq 1}\right]
$$




$$
=\exp (-r T)-\exp (-r T) E^{Q}\left[w\left(X_{T}\right) \mid X_{T} \leq 1\right] F_{T}^{Q}(1 \mid X),
$$

where $E^{Q}$ represents the expectation under the equivalent martingale measure $Q$ conditioning on information currently available. Under this measure,

$$
d X / X=(r-\lambda \nu) d t+\sigma d Z_{1}+(\Pi-1) d Y .
$$

Equation (6) can be rewritten as:

$$
d \ln (X)=\left(r-\sigma^{2} / 2-\lambda \nu\right) d t+\sigma d Z_{1}+\ln (\Pi) d Y .
$$

The expression $F_{T}^{Q}(\xi \mid X)$ is defined as the probability of event $\left\{X_{T} \leq \xi\right\}$ conditional on current $X$ under risk-adjusted probability measure $Q$, i.e., $F_{T}^{Q}(\xi \mid X):=Q\left(X_{T} \leq \xi \mid X\right)$.

Lemma 1 is based on a standard risk-neutrality approach in the derivative pricing literature. Its proof is provided in the appendix.

To evaluate the bond price $B$, a critical step is to calculate the default probability $F_{T}^{Q}(1 \mid X)$. We can prove

Lemma 2 The probability $F_{T}^{Q}(\xi \mid X):=Q\left(X_{T} \leq \xi\right)$ is given by

$$
F_{T}^{Q}(\xi \mid X)=\sum_{i=0}^{\infty} \frac{\exp (-\lambda T)(\lambda T)^{i}}{i !} \cdot N\left(\frac{\ln (\xi)-\ln (X)-\left(r-\sigma^{2} / 2-\lambda \nu\right) T-i \mu_{\pi}}{\sqrt{\sigma^{2} T+i \cdot \sigma_{\pi}^{2}}}\right) .
$$

Proof: See Appendix.

One case of particular interest is that the writedown of a defaulted bond is a linear function of firm value upon default, that is

$$
w(X)=w_{0}-w_{1} X .
$$

For this important case, we have

Theorem 1 If $w(X)=w_{0}-w_{1} X$, then

$$
\begin{gathered}
B(X, T)=\exp (-r T)\left\{1-w_{0} F_{T}^{Q}(1 \mid X)\right. \\
\left.+w_{1} X \sum_{i=0}^{\infty} \frac{\exp (-\lambda T)(\lambda T)^{i}}{i !} \cdot \exp \left[\mu_{i}+\sigma_{i}^{2} / 2\right]\left[1-N\left(\frac{\ln (X)+\mu_{i}+\sigma_{i}^{2}}{\sigma_{i}}\right)\right]\right\}
\end{gathered}
$$


where

$$
\mu_{i}=\left(r-\sigma^{2} / 2-\lambda \nu\right) T+i \mu_{\pi},
$$

and

$$
\sigma_{i}:=\sqrt{\sigma^{2} T+i \cdot \sigma_{\pi}^{2}}
$$

$F_{T}^{Q}(1 \mid X)$ is the probability of default as given in Lemma 2.

The proof of the theorem is provided in the appendix.

The closed form expression of bond price $B(X, T)$ for the writedown $w(X)=w_{0}-$ $w_{1} X$ involves nothing more complicated than standard normal distribution functions. Its structure is similar to that of European option prices when the underlying asset prices follow jump-diffusion processes. (See Merton (1976).)

We can define the recovery rate of a defaulted bond as $q(X)=1-w(X)$. If $w(X)=$ $w_{0}-w_{1} X$, then $q(X)=\left(1-w_{0}\right)+w_{1} X=q_{0}+q_{1} X$. If $q_{0}<0$ (i.e., $\left.w_{0}>1\right), q(X)=q_{0}+q_{1} X$ can be negative. For a limited-liability bond, a negative value of bond is precluded. A reasonable assumption to avoid a negative value of $q(X)$ is that

$$
q(X)=\max \left(0, q_{0}+q_{1} X\right)
$$

This is equivalent to

$$
w(X)=\min \left(1, w_{0}-w_{1} X\right)
$$

It is easy to see that $w^{\prime}(X) \leq 0$ for $X \geq 0$ whenever $w_{1} \geq 0$.

Theorem 2 Assume $w(X)=\min \left(1, w_{0}-w_{1} X\right)$. If $w_{0}>1$ but $w_{0}-w_{1}<1$, then

$$
\begin{aligned}
B(X, T)= & \exp (-r T)\left\{1-F_{T}^{Q}(1 \mid X)+\left(1-w_{0}\right)\left[F_{T}^{Q}(1 \mid X)-F_{T}^{Q}\left(\frac{w_{0}-1}{w_{1}} \mid X\right)\right]\right. \\
& +w_{1} X \sum_{i=0}^{\infty} \frac{\exp (-\lambda T)(\lambda T)^{i}}{i !} \cdot \exp \left[\mu_{i}+\sigma_{i}^{2} / 2\right] \\
& \left.\cdot\left[N\left(\frac{\ln (X)+\mu_{i}+\sigma_{i}^{2}-\ln \left(\left(w_{0}-1\right) / w_{1}\right)}{\sigma_{i}}\right)-N\left(\frac{\ln (X)+\mu_{i}+\sigma_{i}^{2}}{\sigma_{i}}\right)\right]\right\}
\end{aligned}
$$

where $\mu_{i}, \sigma_{i}$ and $F_{T}^{Q}(. \mid X)$ are defined as in Theorem 1.

The proof of this theorem is similar to that of Theorem 1. See the appendix for details. 
The bond price with the limited-liability restriction given in Theorem 2 involves no more complicated mathematics than that given in Theorem 1 for the bonds without limitedliability restriction, even though the price formula with the limited-liability restriction looks longer and less attractive. One can easily prove that bond price $B(X, T)$ with limitedliability is higher than that without limited-liability restriction, ceteris paribus. This is very intuitive, with limited liability, bondholders do not have to pay anyone else even in the worst cases.

Figure 1 shows the effect of limited-liability constraint on credit spreads. One can see from the figure that the impact of such a constraint may be very small under reasonable parameter values. This is because the probability that $1-w$ becomes negative is relatively low. For this reason, we will not impose this constraint in subsequent analyses so as to simplify the exposition.

\section{On the Solution to the General Model}

In this section, we consider our general model (under Assumptions 1-7) in which a default can occur at any point of time. ${ }^{8}$

Let $\tau$ represent the time when a default occurs. Mathematically,

$$
\tau:=\inf \left\{t \mid X_{t} \leq 1, t \geq 0\right\}
$$

that is, $\tau$ is the first passage time for $X_{t}$ to cross the lower bound 1. Explicit solutions for first passage times are not known, except for some very special diffusion processes. ${ }^{9}$

If a default occurs before or at the maturity of the bond, i.e., $\tau \leq T$, the payoffs to the bondholders will be affected by the default. A bond will receive a value of $1-w\left(X_{\tau}\right)$ at the maturity $T$. If $X$ is a continuous diffusion process as in Longstaff and Schwartz (1995), $X_{\tau}$ will be always equal to 1 . If $X$ is discontinuous, $X_{\tau}$ will be a random number and its distribution will generally depend on the stopping time $\tau$.

\footnotetext{
${ }^{8}$ In the following discussions, a general model will refer to a model in which a default occurs immediately when the firm's value reaches a lower bound, while a simplified model will refer to a model in which a default can only occur at the maturity of the bond.

${ }^{9}$ See Abrahams (1986) for a survey on the first passage time problem.
} 
Using the results in the previous section, we know that the bond price $B(X, T)$ satisfies the partial differential equation (4)

$$
\frac{1}{2} \sigma^{2} X^{2} B_{X X}+(r-\lambda \nu) X B_{X}-r B+\lambda E_{t}[B(X \Pi, T)-B(X, T)]=B_{T},
$$

subject to

$$
B(X, 0)=I_{\tau>T}+\left[1-w\left(X_{\tau}\right)\right] I_{\tau \leq T}
$$

at $T=0$.

A Feyman-Kac solution to the above PDE, similar to Lemma 1, can be expressed as

$$
B(X, T)=\exp (-r T)-\exp (-r T) E^{Q}\left[w\left(X_{\tau}\right) I_{\tau \leq T}\right]
$$

where $Q$ is the risk-adjusted probability measure under which $X$ follows a jump-diffusion process as described in equation (6).

The following theorem provides a tractable way to valuing the bond in the general framework where a default can occur at any time.

Theorem 3 Assume $X>1$. The bond price $B(X, T)$ given in equation (11) can be expressed as

$$
B(X, T)=\exp (-r T)-\exp (-r T) \lim _{n \rightarrow \infty} \sum_{i=1}^{n} E^{Q}\left[w\left(X_{t_{i}}^{*}\right) \mid \Omega_{i}\right] Q_{i}
$$

where

$$
\begin{gathered}
t_{i}=\frac{i}{n} T \\
\Omega_{i}=\left\{X_{t_{i}}^{*} \leq 1 \text { and } X_{t_{j}}^{*}>1, \forall j<i\right\} \\
Q_{i}=Q\left(\Omega_{i}\right),
\end{gathered}
$$

and moreover, $X_{t_{i}}^{*}$ is defined recursively as

$$
\begin{gathered}
X_{t_{0}}^{*}=X, \\
\ln \left(X_{t_{i}}^{*}\right)-\ln \left(X_{t_{i-1}}^{*}\right)=x_{i}+y_{i} \cdot \pi_{i}, \quad i=1,2, \cdots, n .
\end{gathered}
$$

Here $x_{i}, y_{i}$, and $\pi_{i}$ are mutually and serially independent random variables drawn from

$$
x_{i} \sim N\left(\left(r-\sigma^{2} / 2-\lambda \nu\right) T / n, \sigma^{2} \cdot T / n\right),
$$




$$
\pi_{i} \sim N\left(\mu_{\pi}, \sigma_{\pi}^{2}\right)
$$

and

$$
y_{i}=\left\{\begin{array}{l}
0, \text { with prob. } 1-\lambda \cdot T / n \\
1, \text { with prob. } \lambda \cdot T / n
\end{array}\right.
$$

Briefly speaking, the theorem holds because in a very small time period, there is no more than one jump can occur and the diffusion process can not move a large distance almost surely. The proof of the theorem is outlined in the appendix.

One feature of Theorem 3 is that the writedown $w(X)$ in the event of default can be any continuous function. Another feature is that the movement of $X_{t}$ is governed by two simple probability distributions: normal distributions and two-point distributions. In particular, a two-point distribution is generally much simpler than a multi-valued Poisson distribution in both theoretical and numerical analyses.

We now describe a simple Monte Carlo approach to valuing $B(X, T)$ based on the theorem.

Procedures to valuing the bond price $B(X, T)$ :

- Step (1). Divide the time interval $[0, T]$ into $n$ equal subperiods for sufficiently large $n$, say $n=100$ or $n=500$. Denote $t_{i}:=T \cdot i / n$.

- Step (2). Do Monte Carlo simulations by repeating the following sub-procedures for $M(j=1,2, \cdots, M)$ times. Typically, one can choose $M$ between 10,000 and 100,000.

a) For each $j$, generate a series of mutually and serially independent random vectors $\left(x_{i}, \pi_{i}, y_{i}\right)$ for $i=1,2, \cdots n$ according to distributions described in Theorem 3.

b) Let $X_{t_{0}}^{*}=X$ and calculate $\ln \left(X_{t_{i}}^{*}\right)$ or $X_{t_{i}}^{*}$ according to the formula

$$
\ln \left(X_{t_{i}}^{*}\right)=\ln \left(X_{t_{i-1}}^{*}\right)+x_{i}+y_{i} \cdot \pi_{i}
$$

for $i=1, \cdots, n$.

c) Find the smallest integer $i \leq n$ such that $\ln \left(X_{t_{i}}^{*}\right) \leq 0 .{ }^{10}$ If such an $i$ exists, let $W_{j}=w\left(X_{t_{i}}^{*}\right)$. Otherwise, $W_{j}=0$.

\footnotetext{
${ }^{10}$ Mathematically, $t_{i}$ obtained in this way is the first passage time of $X_{t}$ to the lower bound 1 in a discretized model.
} 
- Step (3). Let $B(X, T)=\exp (-r T)\left(1-\sum_{j=1}^{M} W_{j} / M\right)$. $B(X, T)$ will be a numerical solution to the bond price.

The above numerical procedure involves nothing more complex than generating $3 n \cdot M$ random numbers based on the simplest probability distributions. It takes only several minutes to value a bond with, for example, a SPARC 20 computer.

\section{Empirical Implications of the Jump-Diffusion Model}

The following numerical examples illustrate some of the rich implications of the jumpdiffusion model.

First, we show the effects of a jump component on the pricing of default-risky bonds. To do this, we keep the instantaneous volatility of firm's value $(\operatorname{Var}(d \ln (X)) / d t)$ constant as we change the parameter values which govern the random components of $d X$, so that the variations in bond prices are truly caused by the relative importance of the jump component rather than by the changes in the overall volatility of firm's value.

Equation (7) implies that

$$
\sigma_{X}^{2}:=\operatorname{Var}(d \ln (X)) / d t=\sigma^{2}+\lambda \cdot \sigma_{\pi}^{2}
$$

if $\mu_{\pi}=0$. We will keep $\mu_{\pi}=0$ and $\sigma_{X}^{2}=0.035$ in our numerical simulations so that the results shown here are really driven by the change in the extent of "discontinuity" of the firm's value process rather than by the variation in the volatility of the firm's value.

As is well known, a diffusion process has a continuous sample path and cannot cross a boundary from somewhere else instantaneously. Therefore, under a diffusion process, if a firm is not currently in financial distress $(X>1)$, its probability of defaulting on very short-term debt is zero and therefore the marginal default probability curve of the firm is upward-sloping at the beginning, as shown in Figure 2 with $\sigma_{\pi}^{2}=0$. In the real world, the default probabilities of short-term bonds are often much larger than zero. If the evolution of firm value follows a jump-diffusion process, however, the story will be different. Under a jump-diffusion process, a default can happen instantaneously because of a sudden drop in firm value. As a result, a jump-diffusion model can generate many different shapes of 
marginal default probability curves, including upward-sloping, downward-sloping, flat, and hump-shaped. This variety of shapes is consistent with those in Fons (1994).

As for cumulative default probabilities, ${ }^{11}$ in accordance with Figure 2, Figure 3 shows that holding constant the volatility of $X$ and the jump intensity $\lambda$, a firm with a more volatile jump component (i.e., a larger $\sigma_{\pi}^{2}$ ) is more likely to default on its short-maturity bonds than is a firm with a more volatile diffusion component. Interestingly, Figure 3 also illustrates the reverse relation at longer maturities. A firm with a more volatile diffusion component is more likely to default on its long-maturity bonds than is a firm with a more volatile jump component. Because this is a surprising result, we now outline the intuition for it.

For a given $T>0$ which is not very small in magnitude, an increase in the volatility of a diffusion process can substantially increase the probability of default during period $[0, T]$. However, for a jump process, the effect on default probability of the jump size volatility $\sigma_{\pi}^{2}$ is largely limited by the jump intensity $\lambda$. If $\lambda$ is very small such that $\lambda T$ is also a small number, then the probability that there is at least one jump in period $[0, T]$ is approximately $\lambda T$. As a result, no matter how large the jump size volatility $\sigma_{\pi}^{2}$ is, the probability of default in period $[0, T]$ caused by the jump process is always smaller than $\lambda T$, even though $\lambda T$ is already small. In this case, an increase in $\sigma_{\pi}^{2}$ mainly affects the remaining value of a firm upon default and has a very small effect on the default probability. This intuition is made more rigorous in the following concrete example.

Consider two extreme $X$ processes for illustration. The first one is a pure diffusion process with the volatility $\sigma^{2}$ and the second one is a pure jump process with a small jump intensity $\lambda$ and a large volatility of jump amplitude $\sigma_{\pi}^{2}:=\operatorname{Var}(\ln (\Pi))$. We assume that $\sigma^{2}=\lambda \cdot \sigma_{\pi}^{2}=0.035$, same as the volatility of $\ln (X)$ used in Figure 3 .

Denote $F(T)$ as the cumulative distribution function of the first passage time to default for the pure diffusion process and $J(T)$ as the cumulative distribution function of the first passage time to default for the pure jump process, where $T$ is the maturity time and default

\footnotetext{
${ }^{11}$ Cumulative default probabilities reported in this paper are not annualized. They are calculated under risk-adjusted probability measure $Q$. They often look higher than default probabilities of real bonds under the physical probability measure. This is because the drift of a firm's value under the risk-adjusted measure is smaller than the corresponding real drift under the physical measure.
} 
occurs whenever $X$ falls to or below 1. Using the result of Harrison (1990), we have

$$
F(T)=N\left(-\frac{\ln (X)+\left(r-\sigma^{2} / 2\right) T}{\sigma \sqrt{T}}\right)+X^{\left(1-\frac{2 r}{\sigma^{2}}\right)} N\left(-\frac{\ln (X)-\left(r-\sigma^{2} / 2\right) T}{\sigma \sqrt{T}}\right) .
$$

Assuming that $X=2$ at time zero and $r=0.05$ as in Figure 3, we obtain immediately that $F(1)=0.0001$ and $F(10)=0.116$.

There is no explicit expression for $J(T)$. However, in a pure jump process with a positive drift, default must be caused by jumps. Assume that $\lambda=0.01$ and that $\sigma_{\pi}^{2}=0.035 / 0.01=$ 3.50. If $T=1$, then the probability of one jump in $[0, T]$ is about $\lambda T=0.01$ and the probability of two or more jumps in $[0, T]$ is small enough to ignore. If a jump occurs at time $t<1$ and there are no other jumps before $t$, the probability that $X_{t}$ falls to or below 1 is

$$
N\left(-\ln (X) / \sigma_{\pi}\right)=N(-\ln (2) / \sqrt{3.5})=0.36
$$

As a result, we have $J(1) \approx 0.01 \times 0.36=0.0036$.

Now let's consider $T=10$. The probability that there is no jump in the time interval $[0, T]$ is

$$
\exp (-\lambda T)=\exp (-0.01 \times 10)=0.90
$$

That is, the probability that there are one or more jumps in $[0, T]$ is $1-0.90=0.10$. Denote $d$ as the conditional probability of a default if there are jumps. Then we have

$$
J(10)=0.10 \cdot d \ll 0.10
$$

As a matter of fact, no matter how one increases the volatility $\sigma_{\pi}^{2}, J(10)$ is always much smaller than 0.10 .

From the above examples, we see that $J(1) \gg F(1)$ and that $J(10) \ll F(10)$. That is, a jump process is more likely to cause a default over a short horizon but less likely to cause a default over a long horizon than a diffusion process.

Straightforwardly, under a jump-diffusion process, a firm's value $V$ can jump below the boundary $K$ without hitting it. This implies that the remaining value of the firm upon default is random and is possibly less than $K$. If $V$ is stochastic, it is very natural that the recovery rate of a defaulted bond is also stochastic because what bondholders recover upon default depends on the remaining value $(V)$ of the firm. We see from Figure 4 that the 
volatility of writedown increases with the volatility of the jump component, $\sigma_{\pi}^{2}$. Without a jump component, the writedown is deterministic. The standard deviation of the writedown is about 0.15 as $\sigma_{\pi}^{2}=0.25$ and rises to about 0.20 when $\sigma_{\pi}^{2}$ becomes 0.50 . This result reveals another attractive feature of the jump-diffusion model. That is, the model provides a reasonable explanation about why the recovery rates of similar bonds are so volatile and so unpredictable.

Generally, the larger the jump size volatility $\sigma_{\pi}^{2}$ is, the farther $X$ is below 1 on average upon default. (If $X$ follows a pure diffusion process then upon default, $X$ always equals to one.) This implies that average writedowns of bonds are larger when the jump volatility is larger. (Recall that a lower $X$ at default means a lower recovery rate, or a higher writedown.) In the examples shown in Figure $5\left(w_{0}=1.4\right.$ and $\left.w_{1}=1.0\right)$, the average writedown is 0.40 when $\sigma_{\pi}^{2}=0.00$ or there is no jump component. It rises to $0.50-0.55$ when $\sigma_{\pi}^{2}=0.25$ and increases further to about 0.65 when $\sigma_{\pi}^{2}=0.50$. Figure 5 also shows that under a jump-diffusion process, not only the ex post recovery of a bond is not a constant, the ex ante recovery rate of a bond is not a constant either. Because a diffusion process is almost unlikely to cause a default in a short period of time, the defaults of short-term bonds are usually caused by the jump component of the dynamics of firm value. As the maturity gets longer, the probability that a default is caused by the diffusion process becomes larger. If a default is caused by the diffusion component, then $X=1$ upon default; while if a default is caused by the jump component, upon default, $X<1$ with probability one. As a result, under a jump-diffusion process, short-maturity bonds are usually have lower expected recovery rates (higher expected writedowns) than are long-maturity bonds.

Theoretically, default probability and expected recovery rate upon default determine the credit spread on a bond. According to Figure 2, under a diffusion process, if a firm is not currently in financial distress $(X>1)$, its probability of defaulting on very short-term debt is zero and therefore, its short-term debt should have zero credit spreads, as shown in Figure 6 with $\sigma_{\pi}^{2}=0$. This strong implication of diffusion models for credit spreads is not valid in the real world. Credit spreads on typical short term bonds are much larger than zero. As mentioned before, Fons (1994) and Sarig and Warga (1989) even find that the yield spread curves of certain kind of bonds (BB-rated or B-rated) are relatively flat or 
downward sloping. ${ }^{12}$ As illustrated in Figure 6, these yield spread curves are captured by a jump-diffusion model with non-trivial jump components.

Figure 6 shows that jump risks significantly raise credit spreads, especially for bonds with short- to middle-maturities, even holding constant the total volatility of the dynamics of firm value. For example, for a two-year discount bond, the annualized credit spread shown in the figure is only seven basis points when jump component does not exist $\left(\sigma_{\pi}^{2}=0\right)$. The spread rises to 32 basis points as $\sigma_{\pi}^{2}$ becomes 0.25 and rises further to 57 basis points as $\sigma_{\pi}^{2}$ reaches 0.50 . This result suggests that a misspecification of stochastic processes governing the dynamics of firm value, i.e., falsely specifying a jump-diffusion process as a continuous Brownian motion process, may substantially understate the credit spreads of corporate bonds. The results here explain the stylized empirical regularities contained in Jones, Mason, and Rosenfeld (1984). ${ }^{13}$

The frequency of jump occurrences, $\lambda$, is another important parameter in characterizing the jump component. Given the volatility of the jump component, $\lambda \sigma_{\pi}^{2}$, the jump frequency $\lambda$ determines how "discontinuous" the jump process $\Pi d Y$ is. A larger $\lambda$ and a smaller $\sigma_{\pi}^{2}$ mean that jumps occur more frequently but each jump may cause a smaller movement. In other words, the path of the process with a larger $\lambda$ and a smaller $\sigma_{\pi}^{2}$ looks more "continuous" than that of a process with a smaller $\lambda$ but a larger $\sigma_{\pi}^{2}$. Figure 7 plots the relation between credit spreads and the jump intensity parameter $\lambda$ based on a pure jump process in which the instantaneous volatility of $d \ln (X)$ remains constant, i.e., $\sigma_{X}^{2}=\lambda \cdot \sigma_{\pi}^{2}=0.035$. The

\footnotetext{
${ }^{12}$ Helwege and Turner (1995) argue that credit spread curves of many B-rated bonds are still upwardsloping based on a particular data sample, but they cannot reject that some B-rated bonds really have downward-sloping credit spread curves. Moreover, no one suspects that the credit spreads of most shortterm bonds are nonzero. Merton's (1974) model which is based on a diffusion approach can generate a downward-sloping credit spread curve only if the firm is exceptionally highly leveraged, that is, if the firm's debt-ratio is greater than one or in terms of my modeling assumptions, the current $X$ is smaller than one. However, according to Helwege and Turner (1995), the data from Standard and Poor's on median book values of debt-to-capitalization ratios by rating indicate that B-rated and even many CCC-rated firms do not have debt ratios greater than one.

${ }^{13}$ The empirical literature has provided very favorable evidence that jumps are an important feature of asset returns. See, for example, Bates (1996), Jorion (1988), Kon (1984), and Das, Foresi, and Sundaram (1996) for details.
} 
figure shows an interesting pattern between credit spreads and the parameters of the jump process. That is, a large $\lambda$ and a small $\sigma_{\pi}^{2}$ are generally associated with low credit spreads of short-term bonds but high credit spreads of long-term bonds. This pattern is driven by the relation between default probabilities and the structure of jump process as shown in Figure 8. Figure 8 looks similar to Figure 3 and shows that for short-maturity bonds, the more continuous the path of $X$ is, the lower the default probabilities are. This phenomenon is reversed as the maturities of bonds get longer.

Figures 9, 10, and 11 illustrate the relations between firm's $X$ and credit spreads, default probabilities, and expected writedowns, respectively. It is not surprising to see from Figures 9 and 10 that credit spreads and default probabilities decrease with $X$. The farther is firm's value $V$ from threshold level $K$, the smaller is the likelihood of a default. What is interesting here is the non-monotonic relation between $X$ and the expected writedowns as shown in Figure 11.

For bonds with very short maturities, a lower $X$ generally implies a higher writedown or a lower recovery rate. This is because a quick default is generally caused by a jump in $X$. The higher is $X$ before jump, the higher is the expected value of $X$ after jump. For bonds with middle maturities, if $X$ is close to default threshold value, 1 , the expected writedown is low. This is because a default in this case is very likely caused by the diffusion part of $X$ and there is a good chance that $X=1$ (the highest value of $X$ upon default). If current $X$ is sufficiently far away from its threshold value, expected recovery rates will be positively correlated with current $X$. This is because when the current $X$ is sufficiently large, the default of the firm will be mainly caused by the jump component of $X$ process over the middle horizon. As mentioned earlier, the higher is $X$ before jump, the higher is the expected value of $X$ after jump.

Because a firm with a high credit rating usually has a large $X$ before default, the results of Figure 11 may explain why among various investment grade bond issues, the recovery rates of defaulted bonds are positively correlated with bond ratings before defaults (Altman 1989). 


\section{Application: Pricing Credit Default Swaps}

The above theoretical framework for modeling default risks can be conveniently used to price credit derivatives such as credit default swaps, credit spread derivatives, and total return swaps. As an example, we consider the pricing of credit default swaps.

A plain vanilla credit default swap involves the exchange of floating rate payment (say, LIBOR) for a payment contingent on default by a reference firm. It is often used to hedge the credit risk associated with various financial claims such as bank loan or trade credit.

As it is well known, the credit risk of a financial claim is usually characterized by two risk-factors: the default probability and the recovery rate. In practice, the second factor is at least as important as the first one. For example, the default of a large borrower may only cause a small drop in the profit of the lending bank if the bank can recover $95 \%$ percent of its loan to this borrower, but the default may cause a disaster to the bank if the recovery rate is only $20 \%$. The ability of a credit default swap to hedge the credit risk of a claim depends on the relation, in the event of default, between the value of defaulted financial claim and the value of the swap's contingent payment. Obviously, the assumption of a constant recovery rate is not able to capture this relation. That's why an explicit modeling of the recovery rate is interesting and necessary in many applications of credit risk analysis.

The contingent payment of a credit default swap can take on several possible forms. The credit default swap pricing issue is virtually an issue of valuing contingent payments. Assume that the payment contingent on default of a bond is $G\left(X_{\tau}\right)$ made at time $T_{s},{ }^{14}$ where $\tau$ is the time of default and $T_{s}$ is the maturity time of the swap ( $\tau \leq T_{s}$ ). Two approaches can then be used to value this payment. The first approach values the payment directly by using the valuation framework established in the previous sections. Denote $A\left(X, T_{s}\right)$ as the present value of contingent payment $G\left(X_{\tau}\right) . A\left(X, T_{s}\right)$ can be determined by PDE (4) with the following terminal condition at $T_{s}=0$ :

$$
A(X, 0)=G(X) \cdot I_{\tau \leq T_{s}}
$$

Theorem 4 Assume that $X>1$. Suppose that the bond defaults immediately at time $\tau$

\footnotetext{
${ }^{14}$ This assumption is made to let us apply the previous framework more straightforwardly. There is no difficult to price the swap if one assumes that the contingent payment is made at time $\tau$.
} 
when $X_{\tau} \leq 1$. For any continuous function $G(X)$, we have

$$
A\left(X, T_{s}\right)=\exp \left(-r T_{s}\right) \lim _{n \rightarrow \infty} \sum_{i=1}^{n} E^{Q}\left[G\left(X_{t_{i}}^{*}\right) \mid \Omega_{i}\right] \cdot Q_{i},
$$

where

$$
\begin{gathered}
t_{i}=\frac{i}{n} T_{s} \\
\Omega_{i}=\left\{X_{t_{i}}^{*} \leq 1 \text { and } X_{t_{j}}^{*}>1, \quad \forall j<i\right\}, \\
Q_{i}=Q\left(\Omega_{i}\right),
\end{gathered}
$$

and moreover, $X_{t_{i}}^{*}$ is defined recursively as

$$
\begin{gathered}
X_{t_{0}}^{*}=X \\
\ln \left(X_{t_{i}}^{*}\right)-\ln \left(X_{t_{i-1}}^{*}\right)=x_{i}+y_{i} \cdot \pi_{i} .
\end{gathered}
$$

$x_{i}, y_{i}$, and $\pi_{i}$ are mutually and serially independent random variables drawn from

$$
\begin{gathered}
x_{i} \sim N\left(\left(r-\sigma^{2} / 2-\lambda \nu\right) T_{s} / n, \sigma^{2} \cdot T_{s} / n\right), \\
\pi_{i} \sim N\left(\mu_{\pi}, \sigma_{\pi}^{2}\right),
\end{gathered}
$$

and

$$
y_{i}=\left\{\begin{array}{l}
0, \text { with prob. } 1-\lambda \cdot T_{s} / n \\
1, \text { with prob. } \lambda \cdot T_{s} / n
\end{array}\right.
$$

In particular, if $G(X)=g$ is a constant, then

$$
A\left(X, T_{s}\right)=\exp \left(-r T_{s}\right) \cdot g \lim _{n \rightarrow \infty} \sum_{i=1}^{n} Q_{i},
$$

Proof: See Appendix.

The swap price $A\left(X, T_{s}\right)$ can be evaluated easily by the same numerical method as described after Theorem 3 . 


\section{Extension: Stochastic Interest Rates}

We assumed constant riskfree interest rates earlier. We now relax this assumption by assuming that the instantaneous riskfree interest rates follow a diffusion process:

Assumption \%: The dynamics of short-term riskfree rates $r$ are given by

$$
d r=(\zeta-\beta r) d t+\eta d Z_{2}
$$

where $\zeta, \beta$, and $\eta$ are constants and $d Z_{2}$ is a standard Brownian motion. The instantaneous correlation between $d Z_{1}$ in Assumption 1 and $d Z_{2}$ is $\rho d t . d Z_{2}$ is independent of $d Y$ and $\Pi$.

This assumption about the short-term interest rate dynamics is proposed by Vasicek (1977) in his well-known term structure model. It is a straightforward exercise to use other interest rate processes like Cox, Ingersoll, Ross (CIR 1985).

The effect of the correlation between the interest rate movements and the changes in firm's value on credit spreads was first investigated by Longstaff and Schwartz (1995). We now study this issue in a more general economic model. As an example, we will extend the result of Theorem 3 to a setup with stochastic interest rates. All other results in the previous sections can be extended similarly.

Under Assumption 7, the partial differential equation (4) for bond price $B(X, r, T)$ can be rewritten as:

$$
\begin{aligned}
& \frac{1}{2} \sigma^{2} X^{2} B_{X X}+\rho \sigma \eta X B_{X r}+\frac{1}{2} \eta^{2} B_{r r}+(r-\lambda \nu) X B_{X} \\
& \quad-r B+(\alpha-\beta r) H_{r}+\lambda E_{t}[B(X \Pi, r, T)-B(X, r, T)]=B_{T}
\end{aligned}
$$

where $\alpha$ represents the sum of parameter $\zeta$ and a constant representing the market price of interest rate risk.

Suppose that Assumption 5 is effective. That is, the firm defaults immediately when its value $V$ falls to or below the threshold level $K(X \leq 1)$. Then $B(X, r, T)$ will satisfy the following condition at $T=0$ :

$$
B(X, r, 0)=I_{\tau>T}+\left[1-w\left(X_{\tau}\right)\right] I_{\tau \leq T}
$$

Similar to Lemma 1, a Feyman-Kac solution to the PDE can be expressed as:

$$
B(X, r, T)=E^{Q}\left[\exp \left(-\int_{0}^{T} r d t\right)\left(I_{\tau>T}+\left(1-w\left(X_{\tau}\right)\right) I_{\tau \leq T}\right)\right],
$$


where $Q$ is the risk-adjusted probability measure under which

$$
\begin{aligned}
d \ln (X) & =\left(r-\frac{\sigma^{2}}{2}-\lambda \nu\right) d t+\sigma d Z_{1}+\ln (\Pi) d Y \\
d r & =(\alpha-\beta \cdot r) d t+\eta d Z_{2} .
\end{aligned}
$$

The bond price formula given in equation (19) can be evaluated according to the following theorem.

Theorem 5 Denote $D(r, T)$ as the price of the riskfree discount bond which pays $\$ 1$ at time $T$. The bond price $B(X, r, T)$ given in equation (19) can then be expressed as

$$
\left.B(X, r, T)=D(r, T)-\lim _{n \rightarrow \infty} \sum_{i=0}^{n} E^{Q}\left[\exp \left(-\sum_{j=0}^{n} r_{t_{j}}^{*} \cdot T / n\right) w\left(X_{t_{i}}^{*}\right)\right) \mid \Omega_{i}\right] \cdot Q_{i},
$$

where

$$
\begin{gathered}
t_{i}=\frac{i}{n} T \\
\Omega_{i}=\left\{X_{t_{i}}^{*} \leq 1 \text { and } X_{t_{j}}>1, \forall j<i\right\} \\
Q_{i}=Q\left(\Omega_{i}\right)
\end{gathered}
$$

and moreover, $X_{t_{i}}^{*}$ and $r_{t_{i}}^{*}$ are defined recursively as

$$
\begin{gathered}
r_{t_{0}}^{*}=r, \\
X_{t_{0}}^{*}=X, \\
r_{t_{i}}^{*}-r_{t_{i-1}}^{*}=\delta_{i} . \\
\ln \left(X_{t_{i}}^{*}\right)-\ln \left(X_{t_{i-1}}^{*}\right)=x_{i}+y_{i} \cdot \pi_{i} .
\end{gathered}
$$

Here $x_{i}, y_{i}, \delta_{i}$, and $\pi_{i}$ are random variables drawn from

$$
\begin{gathered}
{\left[\begin{array}{c}
\delta_{i} \\
x_{i}
\end{array}\right] \sim N\left(\left[\begin{array}{c}
\alpha-\beta \cdot r_{t_{i-1}}^{*} \\
r_{t_{i-1}}^{*}-\sigma^{2} / 2-\lambda \nu
\end{array}\right] \cdot \frac{T}{n},\left[\begin{array}{cc}
\eta^{2} & \rho \sigma \eta \\
\rho \sigma \eta & \sigma^{2}
\end{array}\right] \cdot \frac{T}{n}\right),} \\
\pi_{i} \sim N\left(\mu_{\pi}, \sigma_{\pi}^{2}\right),
\end{gathered}
$$

and

$$
y_{i}=\left\{\begin{array}{l}
0, \text { with prob. } 1-\lambda \cdot T / n \\
1, \text { with prob. } \lambda \cdot T / n
\end{array}\right.
$$


In the Vasicek term structure model, the riskfree bond price $D(r, T)$ is given by

$$
D(r, T)=\exp (a(T)-b(T) r)
$$

where

$$
\begin{aligned}
a(T)= & \left(\frac{\eta^{2}}{2 \beta^{2}}-\frac{\alpha}{\beta}\right) T+\left(\frac{\eta^{2}}{\beta^{3}}-\frac{\alpha}{\beta^{2}}\right)(\exp (-\beta T)-1) \\
& -\left(\frac{\eta^{2}}{4 \beta^{3}}\right)(\exp (-2 \beta T)-1) \\
b(T)= & \frac{1-\exp (-\beta T)}{\beta} .
\end{aligned}
$$

The intuition of this theorem is similar to that of Theorem 3. Its proof is outlined in the appendix.

One can follow procedures similar to those described after Theorem 3 to evaluate bond price $B(X, r, T)$ numerically.

Figure 12 graphs the relation between credit spreads and the correlation coefficient between the diffusion component of the changes in firm's value and changes in short-term

interest rate. Similar to the results reported by Longstaff and Schwartz (1995), the impact of the correlation coefficient $\rho$ is significant. The reason why the credit spread increases with $\rho$ is that the risk-neutral distribution of future values of $X$ depends on the movements in $r$. Thus, the variance of changes in $X$ depends on the correlation between changes in $X$ and changes in short-term interest rate. When $\rho$ is positive, the covariance term adds to the total variance of changes in $X$ under the risk-adjusted probability measure, and therefore increases the probability of a default, as shown in Figure 13.

\section{Concluding remarks}

This paper develops a tractable yet theoretically rigorous framework for valuing risky debt and credit derivatives that incorporates both default risk and interest rate risk and allows for both a continuous component and a jump component in the evolution of firm value.

The paper has a number of important implications. It shows that the structural pricing model with both a jump component and a continuous component is much richer in generating various shapes of the term structure of credit spreads than are other structural models 
and that a jump-diffusion model can explain a number of empirical regularities regarding default probabilities, recovery rates, and credit spreads which are not captured by traditional diffusion models. It also provides a simple integrated framework in which expected and unexpected defaults can coexist. The results of this paper suggest that both diffusion process and jump process are potentially important components for a structural valuation model for corporate debt.

The valuation framework of the paper can be easily extended to allow for more institutional details such as floating rate coupon payments and bond indenture provision that may require a firm repay its lenders recovered values at default time $\tau$ if a default occurs before the maturity of the bond.

Most structural approaches to modeling corporate debt do not provide practical tools for valuing realistic types of default-risky securities, even though they may provide useful conceptual insights on credit risk. Our model can be easily applied to valuing various types of corporate debt securities and even credit derivatives. The model not only has the flexibility of the reduced-form approach for capturing the basic features of the obserevd credit spreads but also provides the conceptual insights on the mechanism behind default events of the traditional structural approach. 


\section{Appendix}

This appendix outlines the proofs of the theorems presented in the text.

Proof of Lemma 1: The proof is straightforward. From a standard risk-neutrality argument, we know that

$$
B(X, T)=\exp (-r T) E^{Q}\left[I_{X_{T}>1}+\left(1-w\left(X_{T}\right)\right) I_{X_{T} \leq 1}\right] .
$$

The lemma follows immediately from the equality

$$
I_{X_{T}>1}+I_{X_{T} \leq 1}=1 .
$$

Proof of Lemma 2: By the definition,

$$
F_{T}^{Q}(\xi \mid X):=Q\left(X_{T} \leq \xi \mid X\right)=Q\left(\ln \left(X_{T}\right) \leq \ln (\xi) \mid X\right)
$$

Let $Y_{T}$ be the total number of jumps from time 0 to time $T$. We have

$$
\ln \left(X_{T}\right) \mid\left(X, Y_{T}=i\right) \sim N\left(\ln (X)+\left(r-\sigma^{2} / 2-\lambda \nu\right) T+i \mu_{\pi}, \sigma^{2} T+i \sigma_{\pi}^{2}\right) .
$$

A tedious calculation yields

$$
\begin{aligned}
F_{T}^{Q}(\xi \mid X) & =Q\left(\ln \left(X_{T}\right) \leq \ln (\xi) \mid \ln (X)\right) \\
& =\sum_{i=0}^{\infty} Q\left(Y_{T}=i\right) \cdot Q\left(\ln \left(X_{T}\right) \leq \ln (\xi) \mid X, Y_{T}=i\right) \\
& =\sum_{i=0}^{\infty} \frac{\exp (-\lambda T)(\lambda T)^{i}}{i !} \cdot N\left(\frac{\ln (\xi)-\ln (X)-\left(r-\sigma^{2} / 2-\lambda \nu\right) T-i \mu_{\pi}}{\sqrt{\sigma^{2} T+i \cdot \sigma_{\pi}^{2}}}\right)
\end{aligned}
$$

Lemma 3 Assume $\ln (x) \sim N\left(\mu_{x}, \sigma_{x}^{2}\right)$. We have

$$
\begin{aligned}
& E[x \mid a<\ln (x) \leq b] \operatorname{Prob}(a<\ln (x) \leq b) \\
& =\int_{\ln (x)=a}^{b} \exp \left[\mu_{x}+\sigma_{x} z\right] \exp \left(-z^{2} / 2\right) \frac{d z}{\sqrt{2 \pi}} \\
& =\exp \left[\mu_{x}+\sigma_{x}^{2} / 2\right]\left[N\left(\frac{b-\mu_{x}-\sigma_{x}^{2}}{\sigma_{x}}\right)-N\left(\frac{a-\mu_{x}-\sigma_{x}^{2}}{\sigma_{x}}\right)\right] .
\end{aligned}
$$


Proof of Lemma 3: Let $\ln (x)=\mu_{x}+\sigma_{x} \cdot z$, where $z \sim N(0,1)$. The first equality follows directly from the definition of conditional expectations. The second equality holds because

$$
\begin{aligned}
& \int_{\ln (x)=a}^{b} \exp \left[\mu_{x}+\sigma_{x} z\right] \exp \left(-z^{2} / 2\right) \frac{d z}{\sqrt{2 \pi}} \\
& =\exp \left[\mu_{x}\right] \int_{\ln (x)=a}^{b} \exp \left[\sigma_{x} z-z^{2} / 2\right] \frac{d z}{\sqrt{2 \pi}} \\
& =\exp \left[\mu_{x}+\sigma_{x}^{2} / 2\right] \int_{\ln (x)=a}^{b} \exp \left[-\left(z-\sigma_{x}\right)^{2} / 2\right] \frac{d z}{\sqrt{2 \pi}} \\
& =\exp \left[\mu_{x}+\sigma_{x}^{2} / 2\right] \int_{z=\left(a-\mu_{x}\right) / \sigma_{x}}^{\left(b-\mu_{x}\right) / \sigma_{x}} \exp \left[-\left(z-\sigma_{x}\right)^{2} / 2\right] \frac{d z}{\sqrt{2 \pi}} \\
& =\exp \left[\mu_{x}+\sigma_{x}^{2} / 2\right] \int_{z=\left(a-\mu_{x}-\sigma_{x}^{2}\right) / \sigma_{x}}^{\left(b-\mu_{x}-\sigma_{x}^{2}\right) / \sigma_{x}} \exp \left(-z^{2} / 2\right) \frac{d z}{\sqrt{2 \pi}} \\
& =\exp \left[\mu_{x}+\sigma_{x}^{2} / 2\right]\left[N\left(\frac{b-\mu_{x}-\sigma_{x}^{2}}{\sigma_{x}}\right)-N\left(\frac{a-\mu_{x}-\sigma_{x}^{2}}{\sigma_{x}}\right)\right] .
\end{aligned}
$$

Proof of Theorem 1: By Lemma 1, if $w(X)=w_{0}-w_{1} X$, then

$$
\begin{aligned}
B(X, T) & =\exp (-r T)\left\{1-E^{Q}\left[w\left(X_{T}\right) \mid X_{T} \leq 1\right] F_{T}^{Q}(1 \mid X)\right\} \\
& =\exp (-r T)\left\{1-w_{0} F_{T}^{Q}(1 \mid X)+w_{1} \cdot E^{Q}\left(X_{T} \mid X_{T} \leq 1\right) F_{T}^{Q}(1 \mid X)\right\} .
\end{aligned}
$$

To finish the proof, we only need to calculate

$$
E^{Q}\left(X_{T} \mid X_{T} \leq 1\right) F_{T}^{Q}(1 \mid X)
$$

Define

$$
h:=E^{Q}\left(X_{T} \mid X_{T} \leq 1\right) F_{T}^{Q}(1 \mid X)
$$

and

$$
h_{i}=E^{Q}\left(X_{T} \mid X_{T} \leq 1, Y_{T}=i\right) Q\left(X_{T} \leq 1 \mid Y_{T}=i, X\right),
$$

where $Y_{T}$ is the total number of jumps from time 0 to time $T$. We have

$$
\begin{aligned}
h & =\sum_{i=0}^{\infty} Q\left(Y_{T}=i\right) h_{i} \\
& =\sum_{i=0}^{\infty} \frac{\exp (-\lambda T)(\lambda T)^{i}}{i !} h_{i} .
\end{aligned}
$$


Using the results of equation (24) and Lemma 3, we obtain

$$
\begin{aligned}
h_{i}= & X \exp \left[\left(r-\sigma^{2} / 2-\lambda \nu\right) T+i \mu_{\pi}+\left(\sigma^{2} T+i \sigma_{\pi}^{2}\right) / 2\right] . \\
& N\left(-\frac{\ln (X)+\left(r-\sigma^{2} / 2-\lambda \nu\right) T+i \mu_{\pi}+\left(\sigma^{2} T+i \sigma_{\pi}^{2}\right)}{\sqrt{\sigma^{2} T+i \sigma_{\pi}^{2}}}\right) .
\end{aligned}
$$

Proof of Theorem 2: Denote $q(X)=1-w(X), q_{0}=1-w_{0}$, and $q_{1}=w_{1}$. By Lemma 1 ,

$$
\begin{aligned}
B(X, T) & =\exp (-r T)\left\{1-E^{Q}\left[w\left(X_{T}\right) \mid X_{T} \leq 1\right] \cdot F_{T}^{Q}(1 \mid X)\right\} \\
& =\exp (-r T)\left\{1-E^{Q}\left[1-q\left(X_{T}\right) \mid X_{T} \leq 1\right] \cdot F_{T}^{Q}(1 \mid X)\right\} \\
& =\exp (-r T)\left\{1-F_{T}^{Q}(1 \mid X)+E^{Q}\left[q\left(X_{T}\right) \mid X_{T} \leq 1\right] \cdot F_{T}^{Q}(1 \mid X)\right\} .
\end{aligned}
$$

The assumption $w(X)=\min \left(1, w_{0}-w_{1} X\right)$ for $0<X \leq 1$ together with $q(X)=1-w(X)$ implies that

$$
q\left(X_{T}\right)= \begin{cases}q_{0}+q_{1} X_{T}, & \text { if }-q_{0} / q_{1}<X_{T} \leq 1, \\ 0, & \text { if } 0<X_{T} \leq-q_{0} / q_{1}\end{cases}
$$

Using equation (24) and Lemma 3, we have immediately

$$
\begin{aligned}
E^{Q}\left[q\left(X_{T}\right) \mid X_{T} \leq 1\right] F_{T}^{Q}(1 \mid X) \\
=E^{Q}\left[q_{0}+q_{1} X_{T} \mid-\frac{q_{0}}{q_{1}}<X_{T} \leq 1\right] \cdot Q\left[-\frac{q_{0}}{q_{1}}<X_{T} \leq 1 \mid X\right] \\
=q_{0} \cdot\left[F_{T}^{Q}(1 \mid X)-F_{T}^{Q}\left(-\frac{q_{0}}{q_{1}} \mid X\right)\right]+q_{1} \sum_{i=0}^{\infty} Q\left(Y_{T}=i\right) \cdot \\
\quad E^{Q}\left[X_{T} \mid-\ln \left(\frac{q_{0}}{q_{1}}\right)<\ln \left(X_{T}\right) \leq 0, Y_{T}=i\right] \cdot Q\left[-\ln \left(\frac{q_{0}}{q_{1}}\right)<\ln \left(X_{T}\right) \leq 0 \mid Y_{T}=i, X\right] \\
=q_{0} \cdot\left[F_{T}^{Q}(1 \mid X)-F_{T}^{Q}\left(-\frac{q_{0}}{q_{1}} \mid X\right)\right]+q_{1} X \sum_{i=0}^{\infty} \frac{\exp (-\lambda T)(\lambda T)^{i}}{i !} \\
\quad \cdot \exp \left[\mu_{i}+\sigma_{i}^{2} / 2\right] \cdot\left[N\left(\frac{\ln (X)+\mu_{i}+\sigma_{i}^{2}-\ln \left(-\frac{q_{0}}{q_{1}}\right)}{\sigma_{i}}\right)-N\left(\frac{\ln (X)+\mu_{i}+\sigma_{i}^{2}}{\sigma_{i}}\right)\right] .
\end{aligned}
$$

Theorem 2 follows directly from the above result.

Proof of Theorem 3: Dividing the time interval $[0, T]$ into $n$ equal subperiods and evaluating expected values on the right hand side of equation (11) gives

$$
E^{Q}\left[w\left(X_{\tau}\right) I_{\tau \leq T}\right]=\sum_{i=1}^{n} E^{Q}\left[w\left(X_{\tau}\right) \mid t_{i-1}<\tau \leq t_{i}\right] \cdot Q\left(t_{i-1} \leq \tau<t_{i}\right),
$$


Denote

$$
\left.\hat{\Omega}_{i}:=\left\{X_{t_{i}} \leq 1 \text { and } X_{t_{j}}>1, j<i\right\}\right)
$$

and

$$
\hat{Q}_{i}:=Q\left(\hat{\Omega}_{i}\right)
$$

It is easy to show that

$$
\begin{aligned}
Q\left(t_{i-1} \leq \tau<t_{i}\right) & =\hat{Q}_{i}+o(T / n) \\
E^{Q}\left[w\left(X_{\tau}\right) \mid t_{i-1}<\tau \leq t_{i}\right] & =E^{Q}\left[w\left(X_{t_{i}}\right) \mid t_{i-1} \leq \tau<t_{i}\right]+O(T / n) \\
& =E^{Q}\left[w\left(X_{t_{i}}\right) \mid \hat{\Omega}_{i}\right]+O(T / n) .
\end{aligned}
$$

On the other hand, equation (7) implies that

$$
\ln \left(X_{t_{i}}\right)-\ln \left(X_{t_{i-1}}\right)=x_{i}+\sum_{j=0}^{\kappa_{i}} \pi_{i j}
$$

where

$$
\begin{gathered}
x_{i} \sim N\left(\left(r-\sigma^{2} / 2-\lambda \nu\right) T / n, \sigma^{2} \cdot T / n\right), \\
\pi_{i j} \sim N\left(\mu_{\pi}, \sigma_{\pi}^{2}\right),
\end{gathered}
$$

and

$$
\kappa_{i}=k, \text { with prob. } \lambda^{k} \cdot \frac{\exp (-\lambda \cdot T / n)}{k !} \cdot(T / n)^{k}, k=0,1, \cdots
$$

According to the definitions of $X_{t_{i}}^{*}$ and $Q_{i}$, we have

$$
\hat{Q}_{i}=Q_{i}+o(T / n)
$$

and

$$
E^{Q}\left[w\left(X_{t_{i}}\right) \mid \hat{\Omega}_{i}\right]=E^{Q}\left[w\left(X_{t_{i}}^{*}\right) \mid \Omega_{i}\right]+o(1)
$$

where $X_{t_{i}}^{*}, \Omega_{i}$ and $Q_{i}$ are defined as before.

As a result, we obtain from equation (31)

$$
E^{Q}\left[w\left(X_{\tau}\right) I_{\tau \leq T}\right]=\lim _{n \rightarrow \infty} \sum_{i=1}^{n} E^{Q}\left[w\left(X_{t_{i}}^{*}\right) \mid \Omega_{i}\right] \cdot Q_{i} .
$$

The theorem then establishes immediately. 
Proof of Theorem 4: Since the contingent payoff at maturity $T_{s}$ of the credit default swap is $G\left(X_{\tau}\right) I_{\tau \leq T_{s}}$, we have

$$
A\left(X, T_{s}\right)=\exp \left(-r T_{s}\right) E^{Q}\left[G\left(X_{\tau}\right) I_{\tau \leq T_{s}}\right]
$$

Using the same method as in the proof of Theorem 3, one obtains immediately

$$
A\left(X, T_{s}\right)=\exp \left(-r T_{s}\right) \lim _{n \rightarrow \infty} \sum_{i=1}^{n} E^{Q}\left[G\left(X_{t_{i}}^{*}\right) \mid \Omega_{i}\right] \cdot Q_{i}
$$

If $G(X)=g$, one has

$$
\begin{aligned}
A\left(X, T_{s}\right) & =\exp \left(-r T_{s}\right) \lim _{n \rightarrow \infty} \sum_{i=1}^{n} E^{Q}\left[g \mid \Omega_{i}\right] \cdot Q_{i} \\
& =\exp \left(-r T_{s}\right) \lim _{n \rightarrow \infty} \sum_{i=1}^{n} g \cdot Q_{i}
\end{aligned}
$$

Proof of Theorem 5: We know that

$$
\begin{aligned}
B(X, r, T) & =E^{Q}\left[\exp \left(-\int_{0}^{T} r d t\right) I_{\tau>T}+\exp \left(-\int_{0}^{T} r d t\right)\left(1-w\left(X_{\tau}\right)\right) I_{\tau \leq T}\right] \\
& =E^{Q}\left[\exp \left(-\int_{0}^{T} r d t\right)\right]-E^{Q}\left[\exp \left(-\int_{0}^{T} r d t\right) w\left(X_{\tau}\right) I_{\tau \leq T}\right] \\
& =D(r, T)-E^{Q}\left[\exp \left(-\int_{0}^{T} r d t\right) w\left(X_{\tau}\right) I_{\tau \leq T}\right] .
\end{aligned}
$$

Using the same method as in the proof of Theorem 3, we then obtain the theorem immediately. 


\section{References}

[1] Abken, P.(1993): "Valuation of default-risky interest-rate swaps," Advances in Futures and Options Research 6, 93-116.

[2] Abrahams, J.(1986): "A survey of recent progress on level crossing problems," in Communications and Networks: A Survey of Recent Advances (edited by I. Blake and H. Poor), Springer-Verlag, 1986.

[3] Altman, E.I.(1989): “Measuring corporate bond mortality and performance," Journal of Finance 44, 909-922.

[4] Altman, E.I.(1992): "Revisiting the high-yield bond market," Financial Management $21,78-92$.

[5] Altman, E.I. and J.C. Bencivenga(1995): "A yield premium model for the high-yield debt market," Financial Analysts Journal September-October 1995, 49-56.

[6] Amin, K.I.(1993): "Jump diffusion option valuation in discrete time," Journal of Finance 48, 1833-1863.

[7] Bates, D.S.(1996): "Jumps and stochastic volatility: Exchange rate processes implicit in Deutsche Mark options," Review of Financial Studies 9, 69-107.

[8] Betker, B.L.(1992): "Management changes, equity's bargain power and deviations from absolute priority in Chapter 11 bankruptcies," Working paper, The Ohio State University.

[9] Black, F. and J.C. Cox(1976): "Valuing corporate securities: Some effects of bond indenture provisions," Journal of Finance 31, 351-367.

[10] Black, F. and M. Scholes(1973): "The pricing of options and corporate liabilities," Journal of Political Economy 81, 637-654.

[11] Chance, D.M.(1990): "Default risk and the duration of zero-coupon bonds," Journal of Finance 45, 265-274. 
[12] Cooper, I. and A. Mello(1991): "The default risk of swaps," Journal of Finance 46, 597-620.

[13] Cox, J.C., J. Ingersoll, and S. Ross(1985): "A theory of the term structure of interest rates," Econometrica 53, 385-407.

[14] Das, S.R. and P. Tufano(1996): "Pricing credit-sensitive debt when interest rates, credit ratings and credit spreads are stochastic," Journal of Financial Engineering.

[15] Das, S.R., S. Foresi, and R.K. Sundaram(1996): "Modeling asset price processes in finance," preprint.

[16] Duffee, G.R.(1996): “On measuring credit risks of derivative instruments," Journal of Banking and Finance.

[17] Duffie, D. and K.J. Singleton(1995): "Modeling term structures of defaultable bonds," Working paper, Stanford University Business School.

[18] Eberhart, A.C., W.T. Moore, and R.L. Roenfeldt(1990): "Security pricing and deviation from the absolute priority rule in bankruptcy proceedings," Journal of Finance 45, 1457-1469.

[19] Fons, J.S.(1994): "Using default rates to model the term structure of credit risk," Financial Analysts Journal, September/October, 25-32.

[20] Franks, J.R. and W. Torous(1989): "An empirical investigation of U.S. firms in reorganization," Journal of Finance 44, 747-769.

[21] Franks, J.R. and W. Torous(1994): "A comparison of financial recontracting in distressed exchanges and Chapter 11 reorganizations," Journal of Financial Economics $35,349-370$.

[22] Geske, R.(1977): “The valuation of corporate liabilities as compound options," Journal of Financial and Quantitative Analysis 12, 541-552.

[23] Harrison, J.M.(1990): Brownian Motion and Stochastic flow systems, Krieger Publishing Company: Florida. 
[24] Harrison, J.M. and S.R. Pliska(1979): "Martigales and arbitrage in multiperiod securities markets," Journal of Economic Theory 20, 281-408.

[25] Helwege, J. and C.M. Turner(1995): "The slope of credit yield curve for speculativegrade issuers," Working paper, Federal Reserve Bank of New York.

[26] Hull, J. and A. White(1992): "The price of default," Risk 5, 101-103.

[27] Jarrow, R.A. D. Lando, and S. Turnbull(1994): "A Markov model for the term structure of credit risk spreads," Working paper, Cornell University.

[28] Jarrow, R.A. and E.R. Rosenfeld(1984): "Jump risks and the intertemporal capital asset pricing model," Journal of Business 57, 337-351.

[29] Jarrow, R.A. and A. Rudd(1983): Option Pricing, Irwin.

[30] Jarrow, R.A. and S. Turnbull(1995): "Pricing derivatives on financial securities subject to credit risk," Journal of Finance 50, 53-86.

[31] Johnson, H. and R. Stulz(1987): "The pricing of options with default risk," Journal of Finance 42, 267-280.

[32] Jones, E.P., S.P. Mason, and E. Rosenfeld(1984): "Contingent claims analysis of corporate capital structures: An empirical investigation," Journal of Finance 39, 611-627.

[33] Jorion, P.(1988): "On jump processes in the foreign exchange and stock markets," Review of Financial Studies 1, 427-445.

[34] Kushner, H.J.(1967): Stochastic Stability and Control, Academic Press, London.

[35] Kim, I.J., K. Ramaswamy, and S. Sundaresan(1992): "The valuation of corporate fixed income securities," Working Paper, New York University.

[36] Kon, S.J.(1984): "Models of stock returns-A comparison," Journal of Finance 39, 147-165.

[37] Leland, H.E. and K.B. Toft(1996): "Optimal capital structure, endogenous bankruptcy, and the term structure of credit spreads," Journal of Finance 51, 987-1019. 
[38] Longstaff, F.A. and E.S. Schwartz(1995): "A simple approach to valuing risky and floating rate debt," Journal of Finance 50, 789-819.

[39] Madan, D.B. and H. Unal(1994): "Pricing the risks of default," Working paper, The Wharton School of the University of Pennsylvania.

[40] Mason, S.P. and S. Bhattacharya(1981): "Risky debt, jump processes, and safety covenants," Journal of Financial Economics 9, 281-307.

[41] Merton, R.C.(1971): "Optimum consumption and portfolio rules in a continuous-time model," Journal of Economic Theory 3, 373-413.

[42] Merton, R.C.(1974): "On the pricing of corporate debt: The risk structure of interest rates," Journal of Finance 29, 449-470.

[43] Merton, R.C.(1976): "Option pricing when underlying stock returns are discontinuous," Journal of Financial Economics 3, 125-144.

[44] Merton, R.C.(1977): "On the pricing of contingent claims and the Modigliani-Miller theorem," Journal of Financial Economics 5, 241-249.

[45] Ramaswamy, K. and S. Sundaresan(1986): "The valuation of floating rate instruments: Theory and evidence," Journal of Financial Economics 17, 251-272.

[46] Sarig, O. and A. Warga(1989): "Some empirical estimates of the risk structure of interest rates," Journal of Finance 44, 1351-1360.

[47] Smith, C.W. and J.B. Warner(1979): "On financial contracting: An analysis of bond covenants," Journal of Financial Economics 7, 117-161.

[48] Vasicek, O.(1977): "An equilibrium characterization of the term structure," Journal of Financial Economics 5, 177-188.

[49] Weiss, L.A.(1990): "Bankruptcy resolution: Direct costs and violation of priority of claims," Journal of Financial Economics 27, 285-314. 


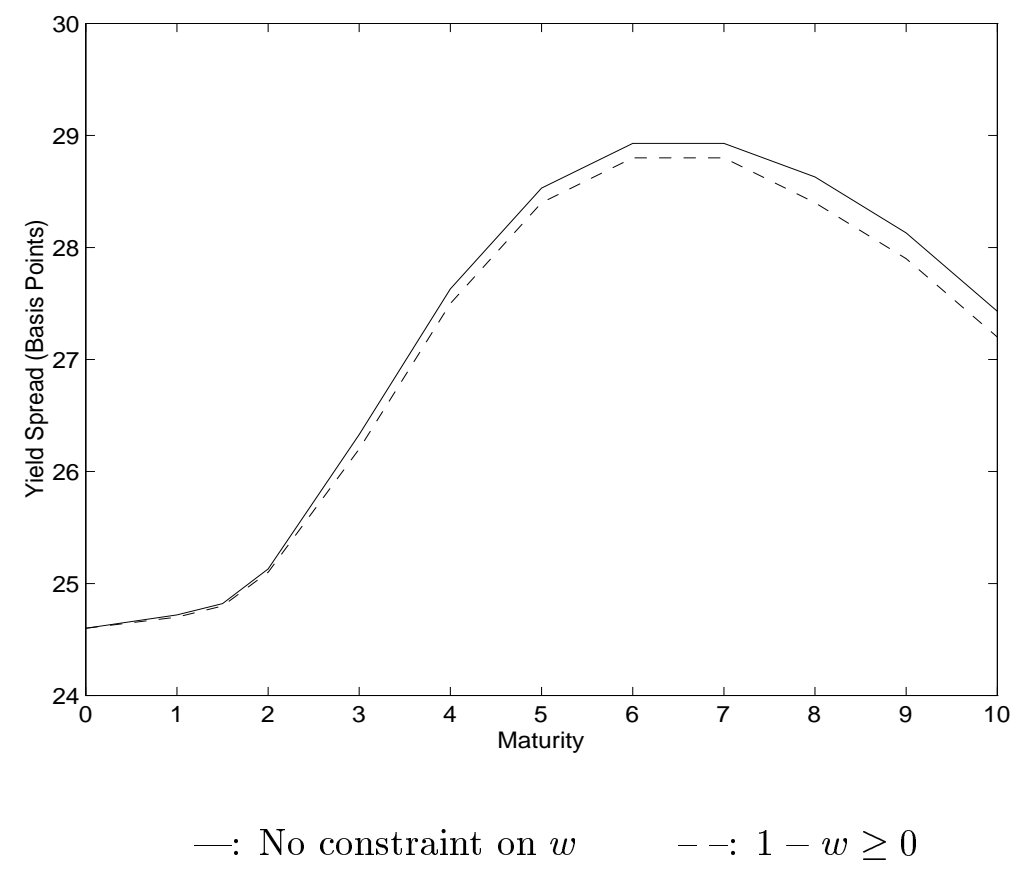

Figure 1: The Effect of Limited Liability Constraint on Credit Spreads. The parameter values used are $X=2.0, r=0.05, \sigma^{2}=0.0225, \lambda=0.05, \mu_{\pi}=0.0, \sigma_{\pi}^{2}=0.25$, $w_{0}=1.4$, and $w_{1}=1.0$. 


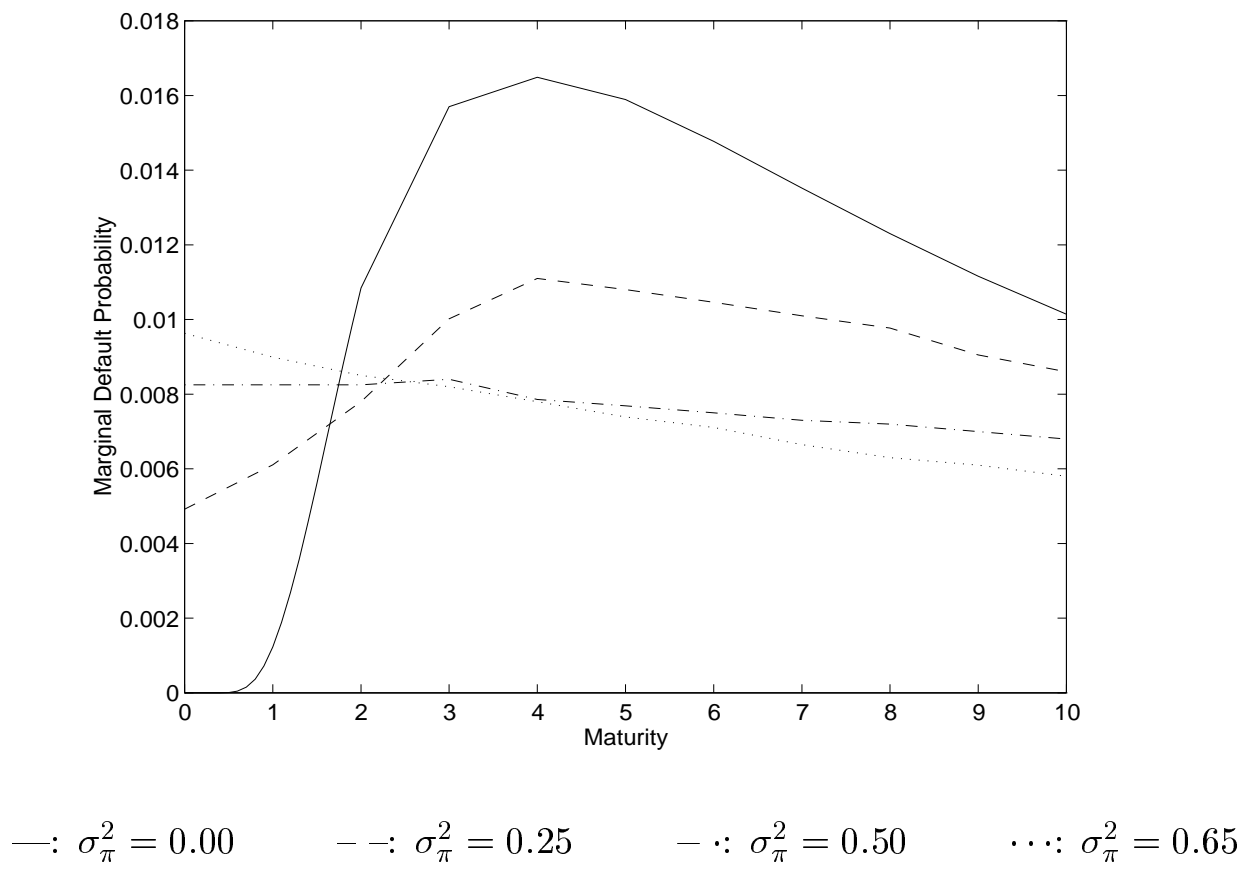

Figure 2: The Relationship between Marginal Default Probabilities and Jump Size Volatility $\sigma_{\pi}^{2}$. The parameter values used are $X=2.0, r=0.05, \lambda=0.05, \mu_{\pi}=0.0$, $\sigma_{X}^{2}=0.035, w_{0}=1.4, w_{1}=1.0$, and $\sigma^{2}=\sigma_{X}^{2}-\lambda \cdot \sigma_{\pi}^{2}$. 


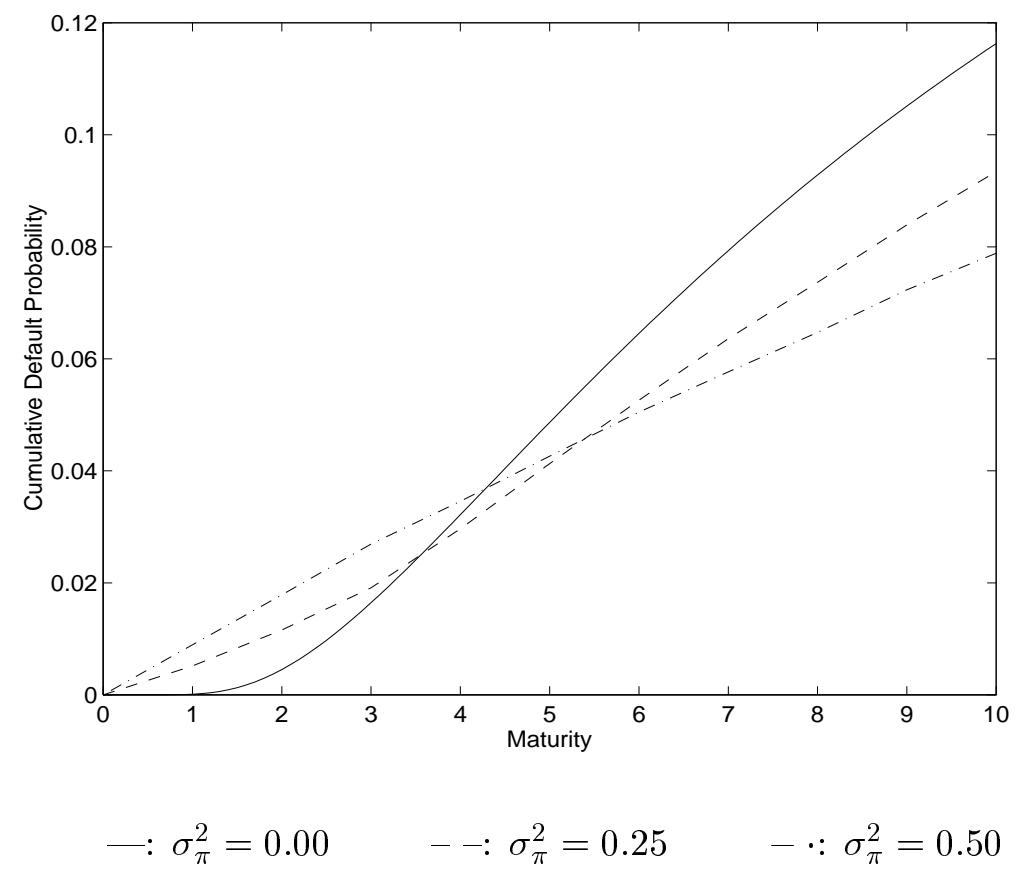

Figure 3: The Relationship between Cumulative Default Probabilities and Jump Size Volatility $\sigma_{\pi}^{2}$. The parameter values used are $X=2.0, r=0.05, \lambda=0.05, \mu_{\pi}=0.0$, $\sigma_{X}^{2}=0.035, w_{0}=1.4, w_{1}=1.0$, and $\sigma^{2}=\sigma_{X}^{2}-\lambda \cdot \sigma_{\pi}^{2}$. 


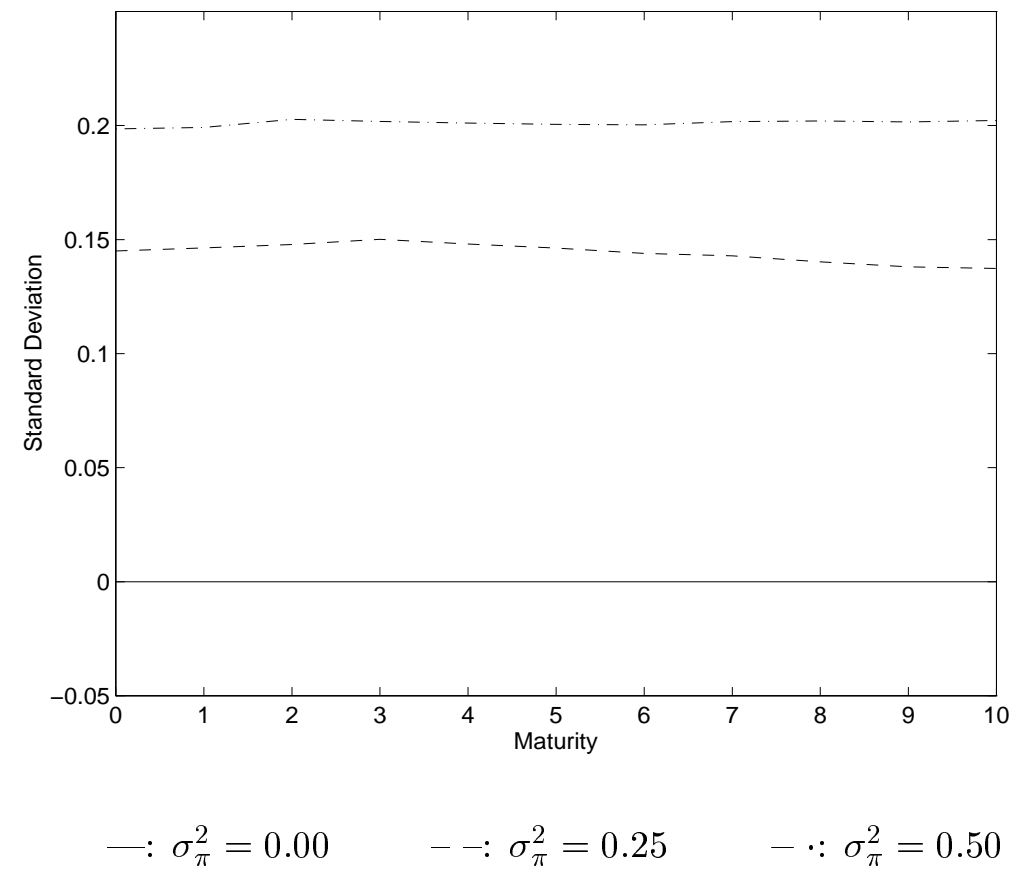

Figure 4: The Effect of Jump Size Volatility $\sigma_{\pi}^{2}$ on the Volatility of Writedown.

The parameter values used are $X=2.0, r=0.05, \lambda=0.05, \mu_{\pi}=0.0, \sigma_{X}^{2}=0.035, w_{0}=1.4$, $w_{1}=1.0$, and $\sigma^{2}=\sigma_{X}^{2}-\lambda \cdot \sigma_{\pi}^{2}$. 


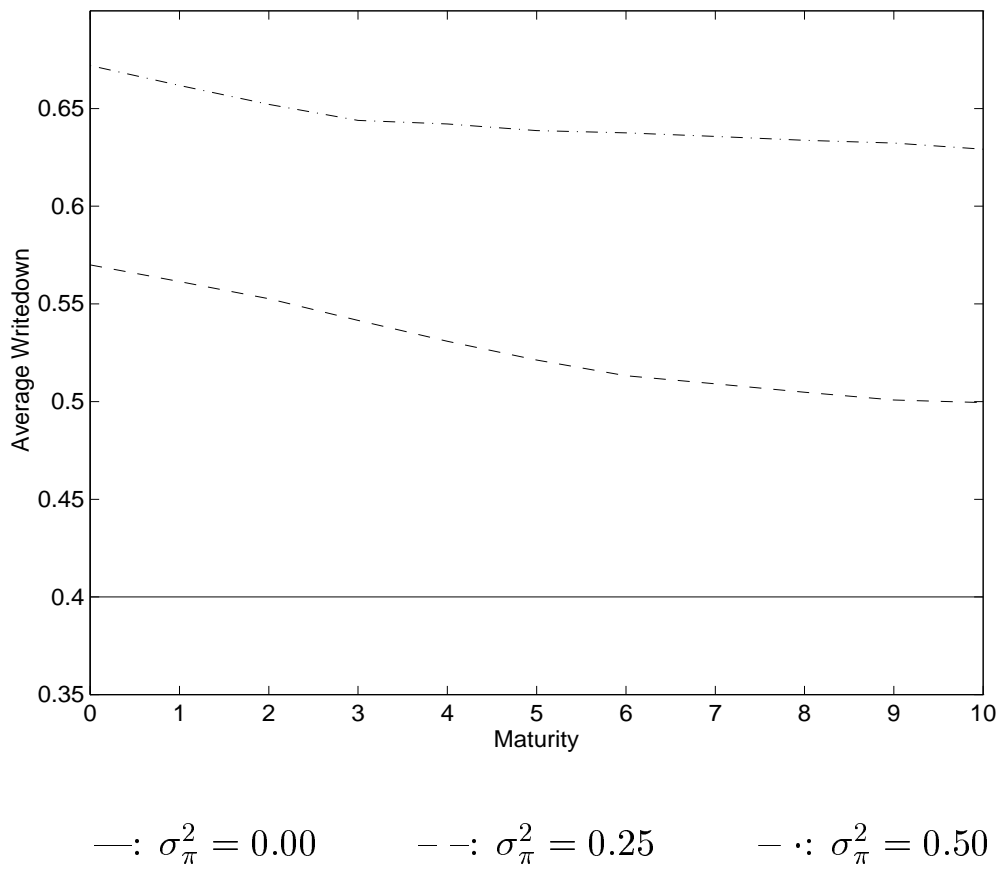

Figure 5: The Relationship between Jump Size Volatility $\sigma_{\pi}^{2}$ and Expected Writedown. The parameter values used are $X=2.0, r=0.05, \lambda=0.05, \mu_{\pi}=0.0, \sigma_{X}^{2}=0.035$, $w_{0}=1.4, w_{1}=1.0$, and $\sigma^{2}=\sigma_{X}^{2}-\lambda \cdot \sigma_{\pi}^{2}$. 


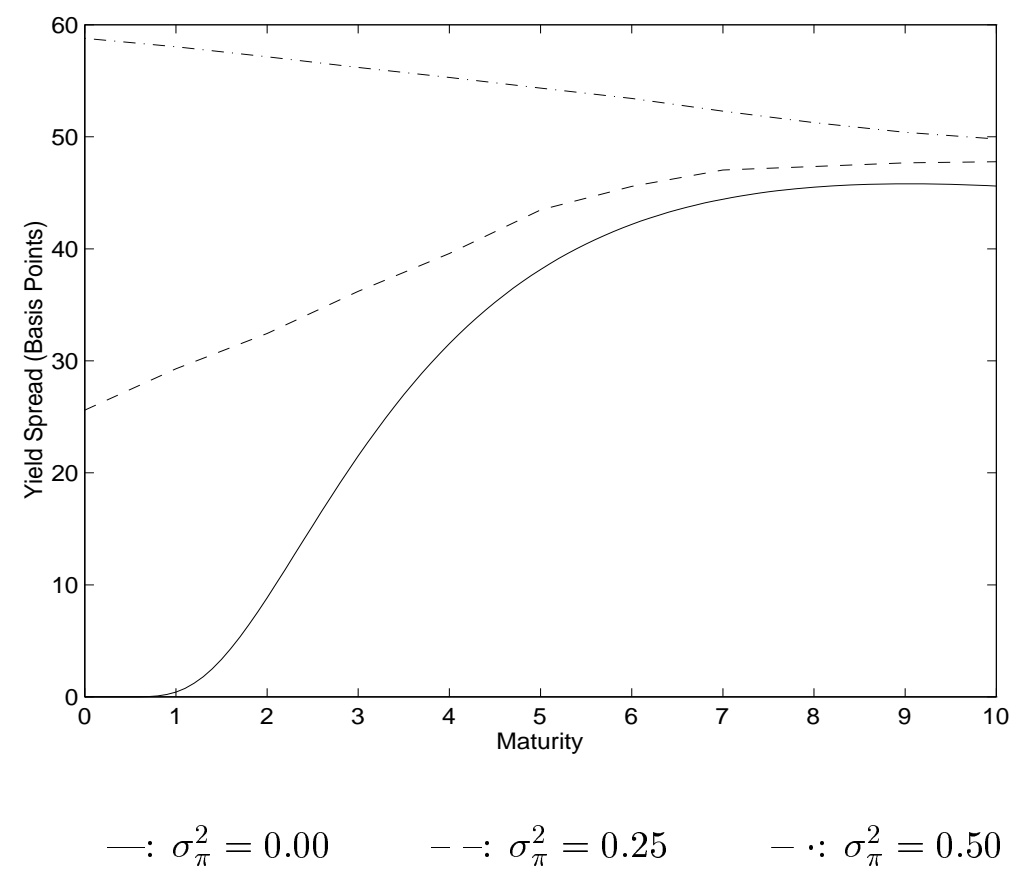

Figure 6: The Relationship between Credit Spreads and Jump Size Volatility $\sigma_{\pi}^{2}$. The parameter values used are $X=2.0, r=0.05, \lambda=0.05, \mu_{\pi}=0.0, \sigma_{X}^{2}=0.035$, $w_{0}=1.4, w_{1}=1.0$, and $\sigma^{2}=\sigma_{X}^{2}-\lambda \cdot \sigma_{\pi}^{2}$. 


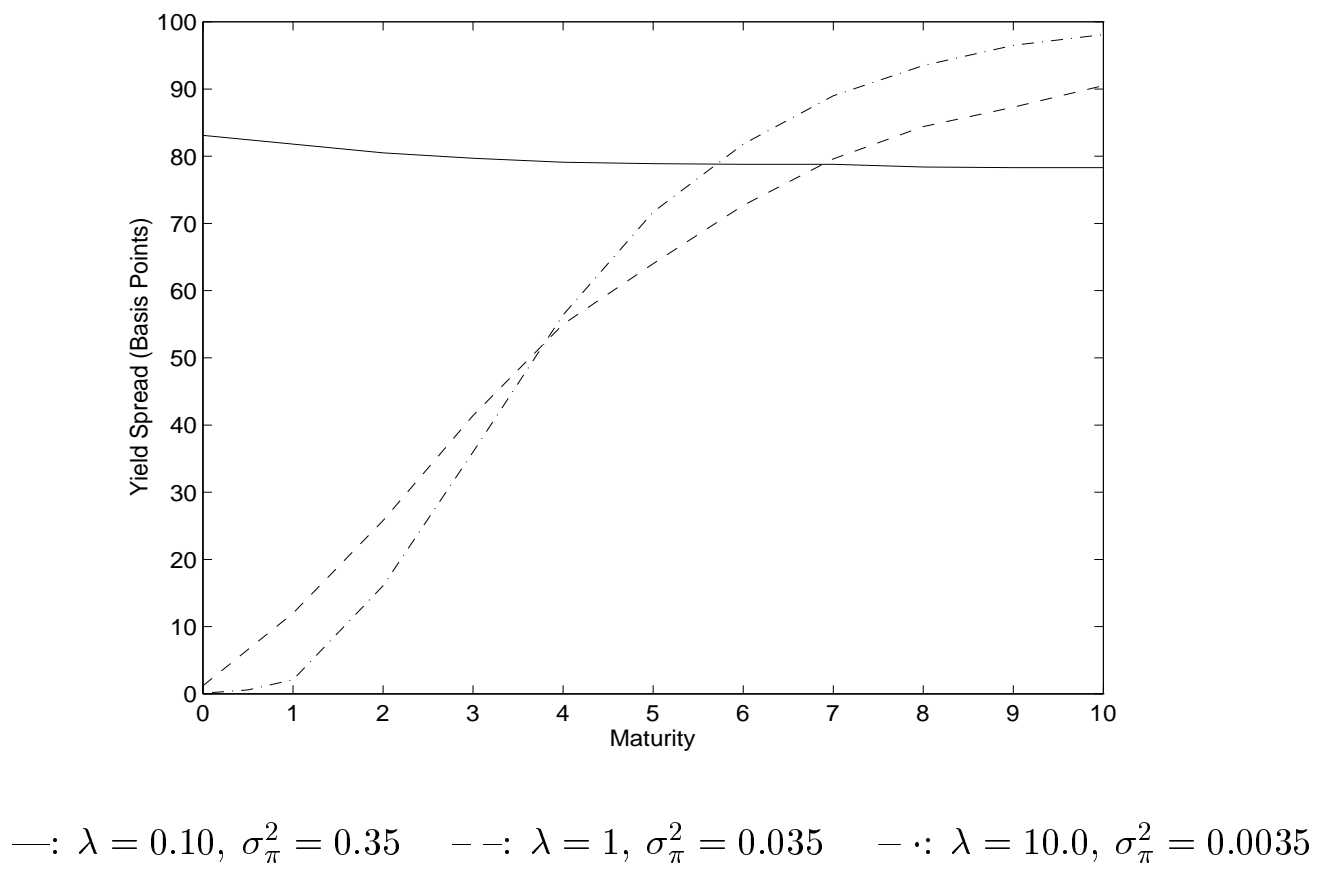

Figure 7: The Relationship between Credit Spreads and Jump Intensity $\lambda$. The parameter values used are $X=2.0, r=0.05, \mu_{\pi}=0.0, \sigma^{2}=0, w_{0}=1.4, w_{1}=1.0$, and $\sigma_{X}^{2}=\sigma^{2}+\lambda \cdot \sigma_{\pi}^{2}=0.035$. 


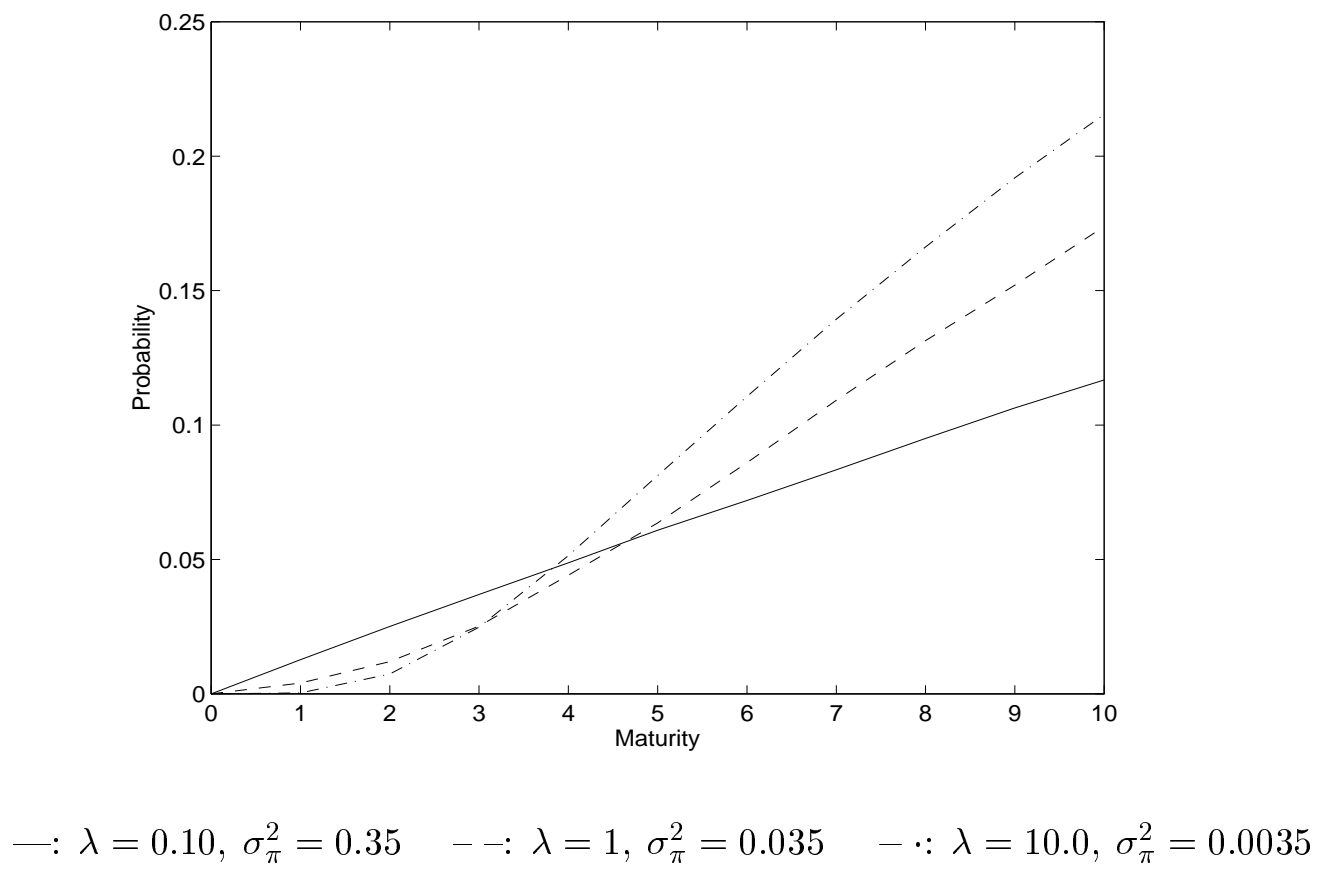

Figure 8: The Relationship between Cumulative Default Probabilities and Jump Intensity $\lambda$. The parameter values used are $X=2.0, r=0.05, \mu_{\pi}=0.0, \sigma^{2}=0, w_{0}=1.4$, $w_{1}=1.0$, and $\sigma_{X}^{2}=\sigma^{2}+\lambda \cdot \sigma_{\pi}^{2}=0.035$. 


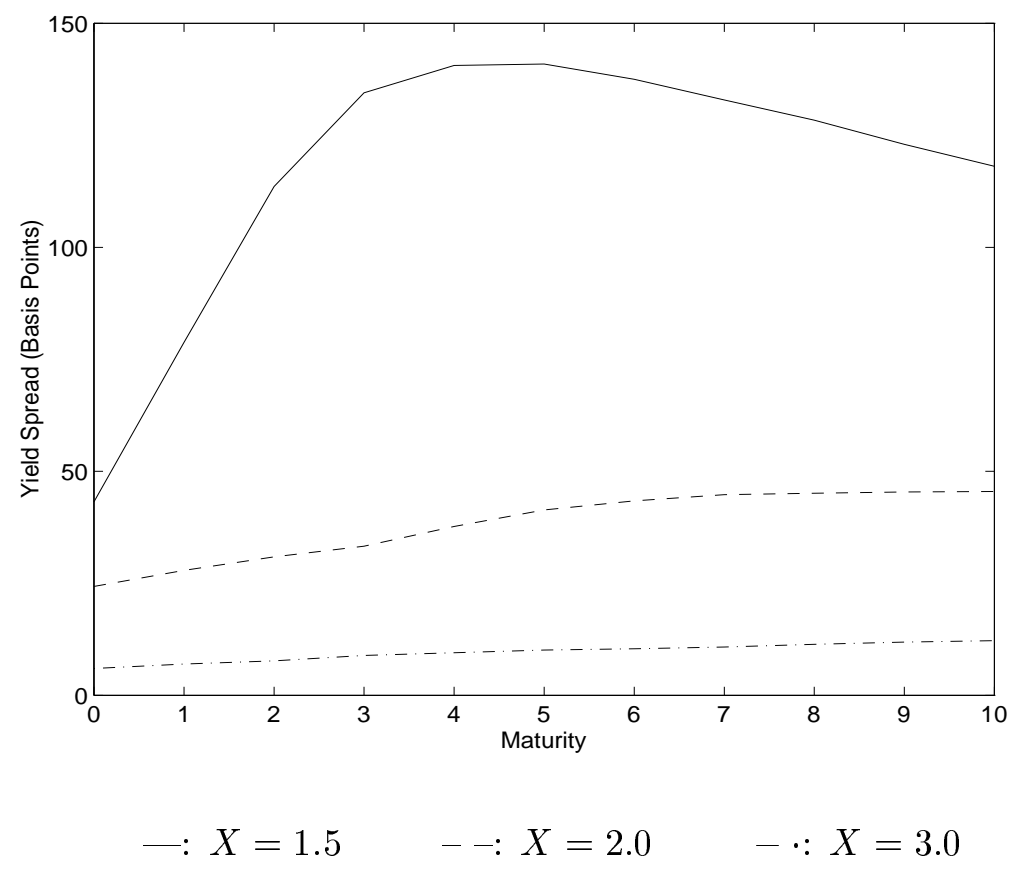

Figure 9: The Relationship between Credit Spreads and Current $X$. The parameter values used are $r=0.05, \lambda=0.05, \sigma^{2}=0.0225, \mu_{\pi}=0.0, \sigma_{\pi}^{2}=0.25, w_{0}=1.4$, and $w_{1}=1.0$. 


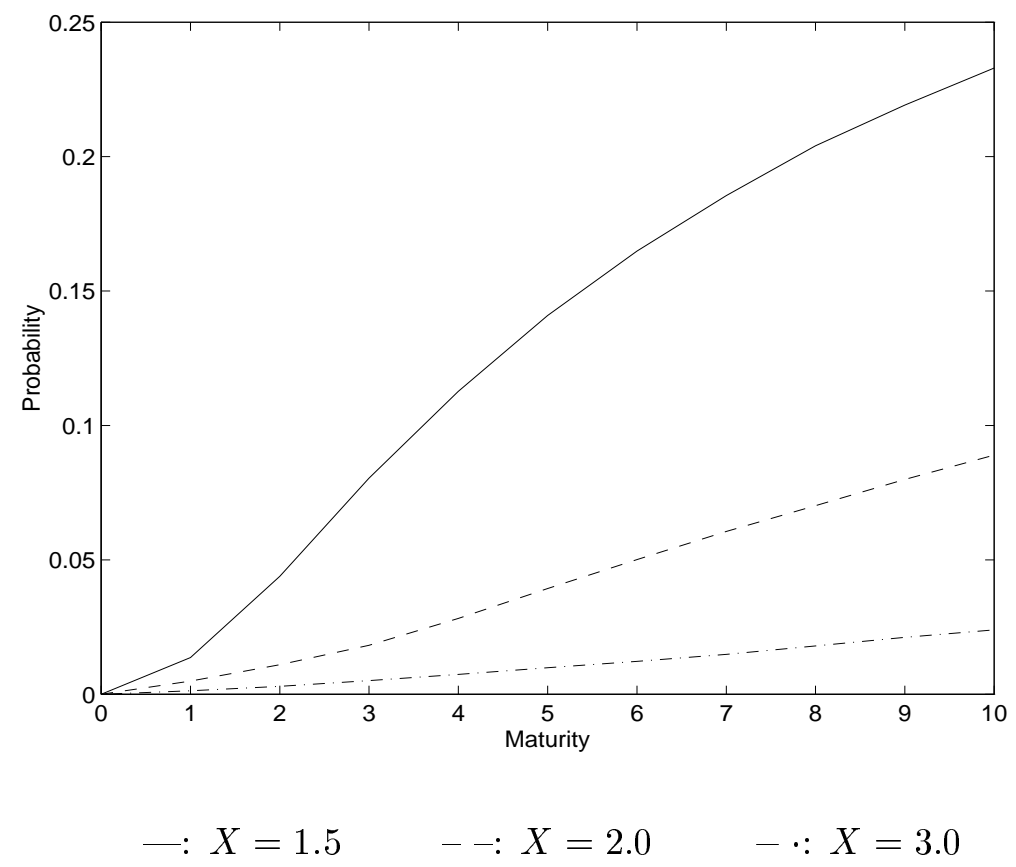

Figure 10: The Relationship between Cumulative Default Probabilities and Current $X$. The parameter values used are $r=0.05, \lambda=0.05, \sigma^{2}=0.0225, \mu_{\pi}=0.0$, $\sigma_{\pi}^{2}=0.25, w_{0}=1.4$, and $w_{1}=1.0$. 


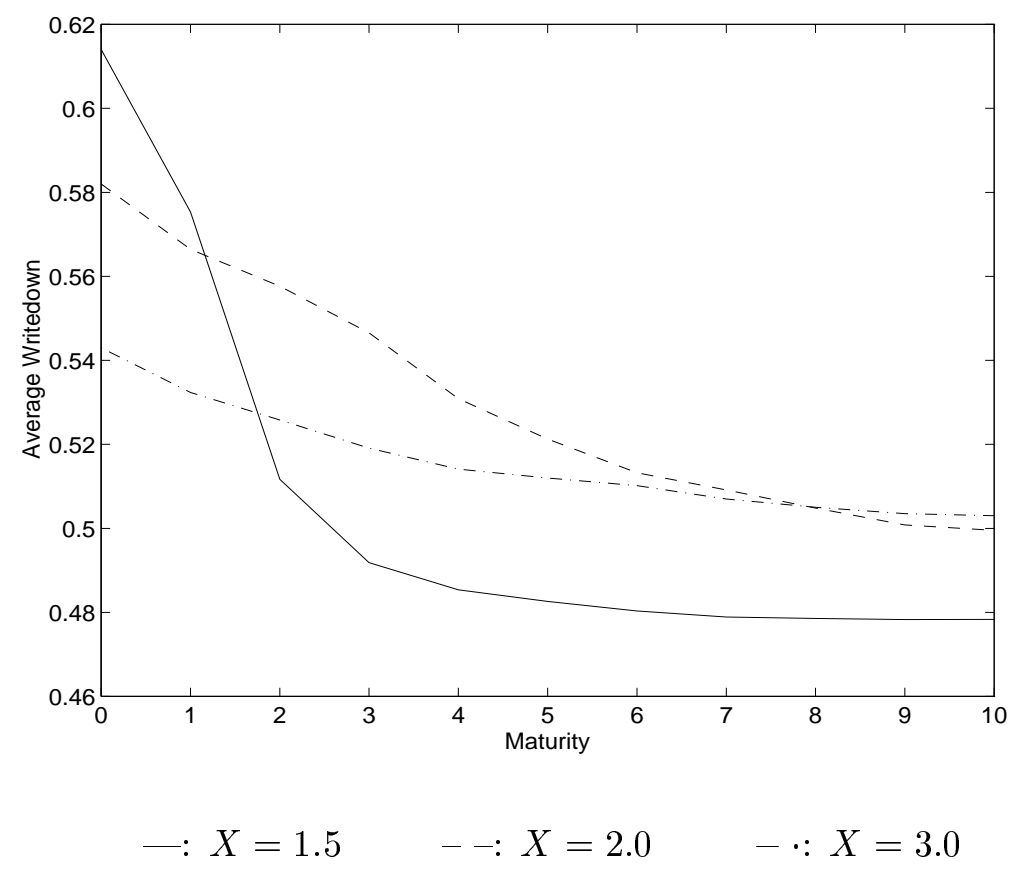

Figure 11: The Relationship between Average Writedown and Current $X$. The parameter values used are $r=0.05, \lambda=0.05, \sigma^{2}=0.0225, \mu_{\pi}=0.0, \sigma_{\pi}^{2}=0.25, w_{0}=1.4$, and $w_{1}=1.0$. 


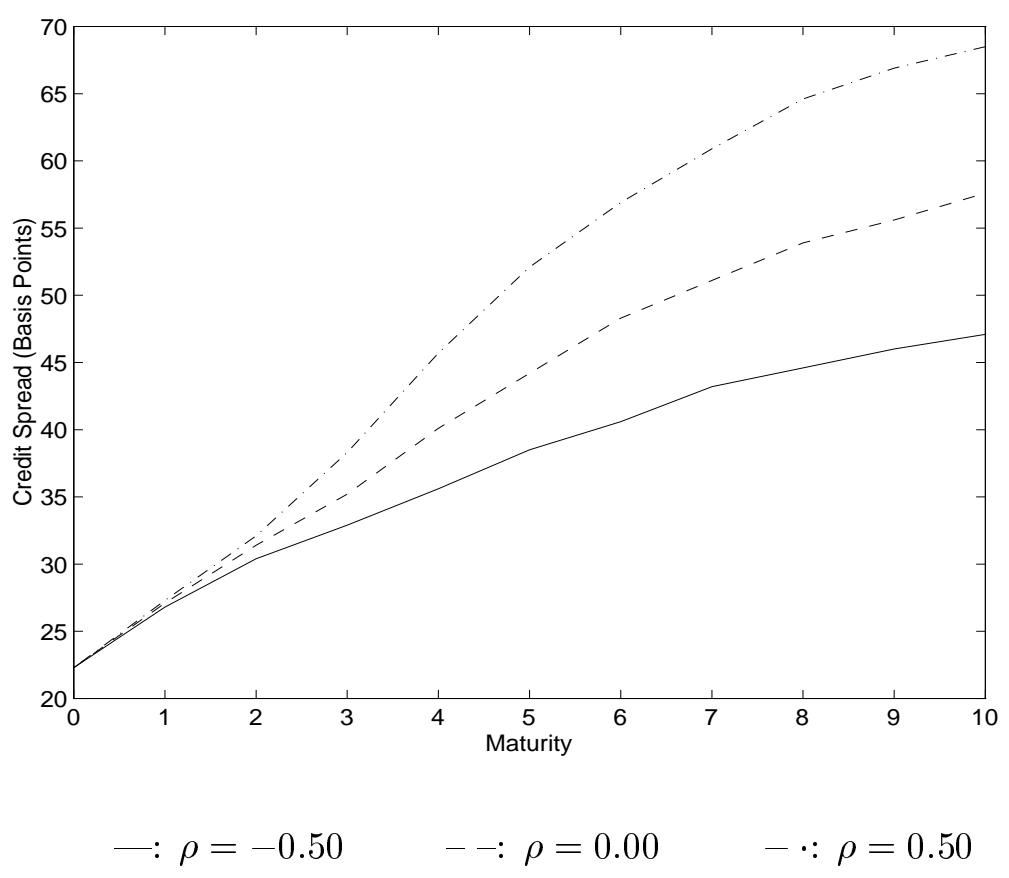

Figure 12: The Effect of Correlation $\rho$ on Credit Spreads. The parameter values used are $X=2.0, r=0.06, \sigma^{2}=0.0225, \lambda=0.05, \mu_{\pi}=0.0, \sigma_{\pi}^{2}=0.25, \sigma_{X}^{2}=0.035$, $w_{0}=1.4, w_{1}=1.0, \alpha=0.05, \beta=1.00$, and $\eta^{2}=0.001$. 


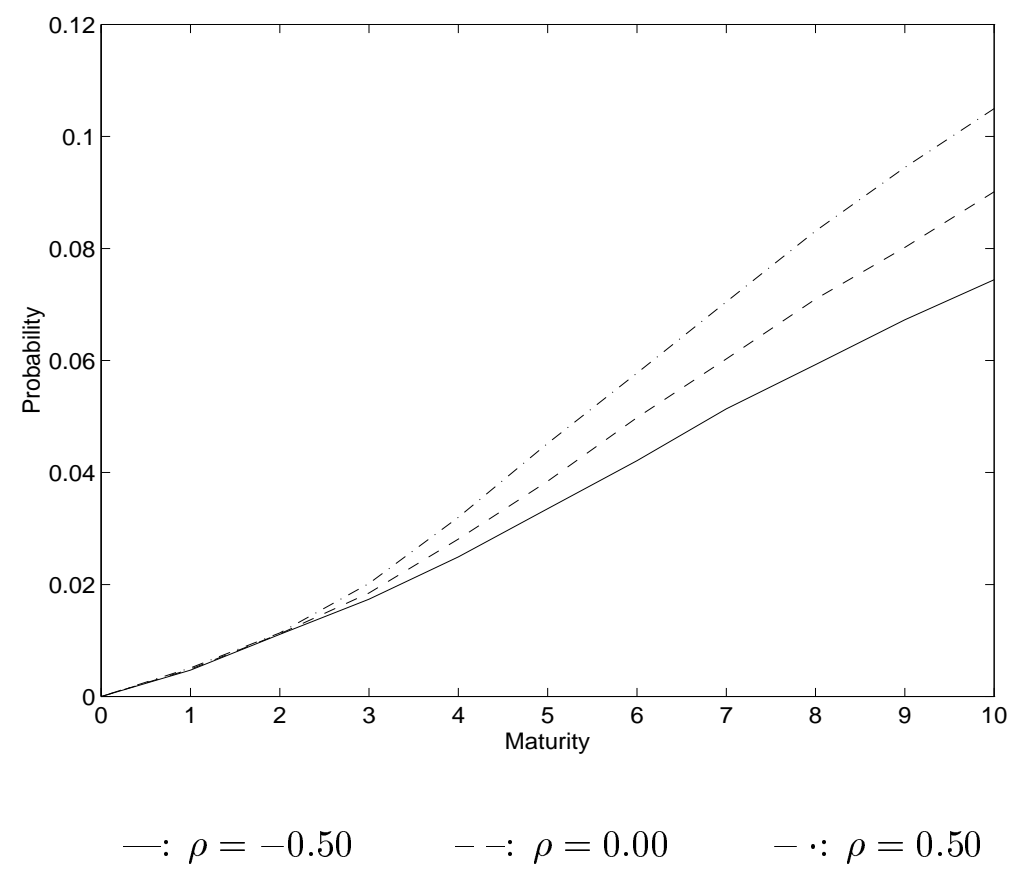

Figure 13: The Effect of Correlation $\rho$ on Default Probabilities. The parameter values used are $X=2.0, r=0.06, \sigma^{2}=0.0225, \lambda=0.05, \mu_{\pi}=0.0, \sigma_{\pi}^{2}=0.25, \sigma_{X}^{2}=0.035$, $w_{0}=1.4, w_{1}=1.0, \alpha=0.05, \beta=1.00$, and $\eta^{2}=0.001$. 